FHWA/IN/JTRP-2006/19

Final Report

FEASIBILITY STUDY FOR BICYCLE SAFETY: DATA ASSESSMENT AND NETWORK EVALUATION

Michael Klobucar

Jon Fricker

August 2007 
Final Report

FHWA/IN/JTRP - 2006/19

\title{
FEASIBILITY STUDY FOR BICYCLE SAFETY: \\ DATA ASSESSMENT AND NETWORK EVALUATION
}

\author{
by \\ Michael Klobucar \\ Research Assistant \\ and \\ Jon D. Fricker \\ Professor and \\ Principal Investigator \\ School of Civil Engineering \\ Purdue University \\ Project No. C-36-59UU \\ File No. 8-5-47 \\ SPR-3032 \\ Prepared in Cooperation with the \\ Indiana Department of Transportation and the \\ U.S. Department of Transportation \\ Federal Highway Administration
}

The contents of this report reflect the views of the authors who are responsible for the facts and the accuracy of the data presented herein. The contents do not necessarily reflect the official views or policies of the Federal Highway Administration and the Indiana Department of Transportation. The report does not constitute a standard, specification or regulation.

Purdue University

West Lafayette, Indiana

August 2007 


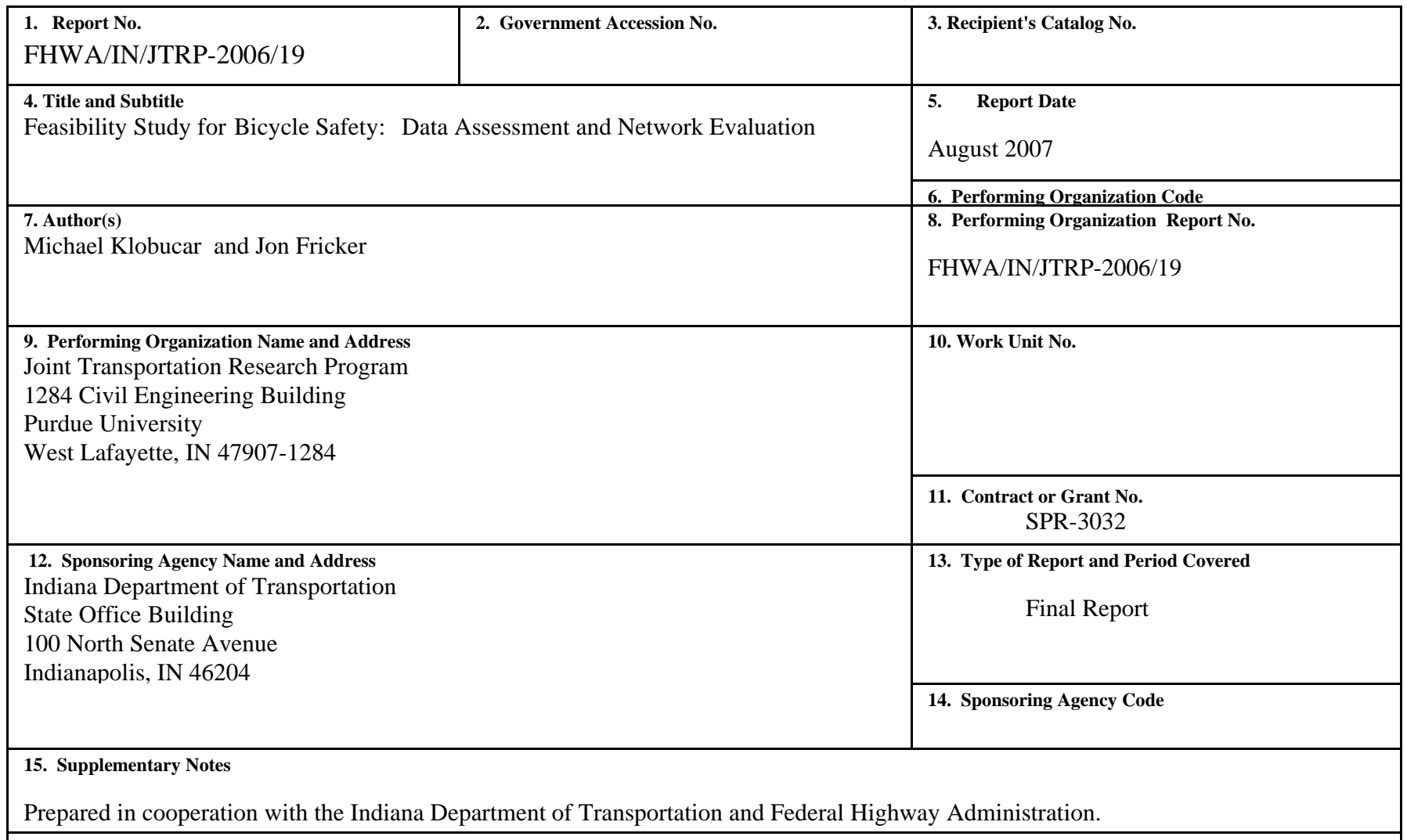

\section{Abstract}

Bicycles offer a promising transportation alternative to private motor vehicles, especially in areas with congestion, poor air quality, and high fuel prices. This study sought rational methods for evaluating the benefits of incorporating bicycle-friendly features into highway project designs. Data on recent bicyclist fatalities and other collisions involving bicyclists in Indiana were analyzed to determine factors that could help to explain the incidents and offer insights into countermeasures or remedies. Human error - on the part of the bicyclist or the motorist - was found to be the most common factor. Poor lighting and noncompliance with sidewalk ordinances also were frequent causes of bicycle crashes. A Bicycle Network Analysis Tool was developed to assess the level of service offered to bicyclists in a study area. The tool uses route length and measures of perceived safety to quantify the bicycle friendliness of a street network. The tool can be used to compare networks and assist in the selection of locations for bicycle facility improvements.

\begin{tabular}{|l|l|l|l|}
\hline $\begin{array}{l}\text { 17. Key Words } \\
\begin{array}{l}\text { Bicycle safety, bicycle crash analysis, bicycle route choice, } \\
\text { bicycle lanes. }\end{array}\end{array} \begin{array}{l}\text { 18. Distribution Statement } \\
\text { No restrictions. This document is available to the public through the } \\
\text { National Technical Information Service, Springfield, VA 22161 }\end{array}$ \\
\hline $\begin{array}{l}\text { 19. Security Classif. (of this report) } \\
\text { Unclassified }\end{array}$ & $\begin{array}{l}\text { 20. Security Classif. (of this page) } \\
\text { Unclassified }\end{array}$ & $\begin{array}{l}\text { 21. No. of Pages } \\
79\end{array}$ \\
\hline
\end{tabular}




\section{ACKNOWLEDGMENTS}

The researchers extend their appreciation to the Indiana Bicycle Coalition and the Indiana Department of Transportation, specifically the study advisory committee, for their helpful input, and to Keth Sapp and everyone at the Center for the Advancement of Traffic Safety for their help in acquiring the crash data, and to the City of West Lafayette for providing the roadway information. 


\section{TABLE OF CONTENTS}

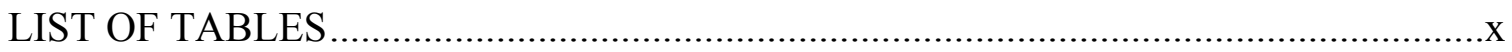

LIST OF FIGURES ..................................................................................... xi

Chapter 1 - Bicycle Crash Analysis .......................................................................... 1

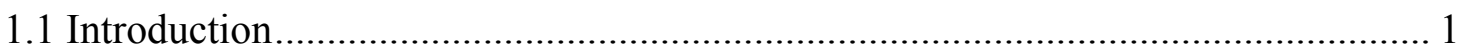

1.2 Statewide Crash Analysis ........................................................................... 1

1.2.1 Statewide Bicycle Crash Data Acquisition ................................................... 1

1.2.2 Bicycle Crash Characteristics ............................................................ 1

1.2.3 Bicycle Crash Demographics.................................................................... 5

1.2.4 Bicycle Crash Database Limitations ............................................................. 9

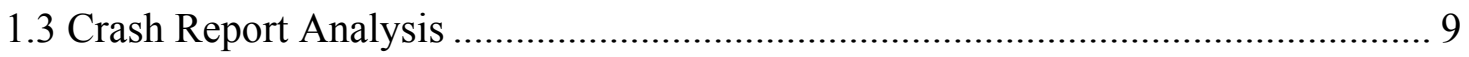

1.4 Bicycle Crash Conclusions and Future Research .......................................... 11

Chapter 2 - Bicycle Network Analysis Tool ............................................................... 14

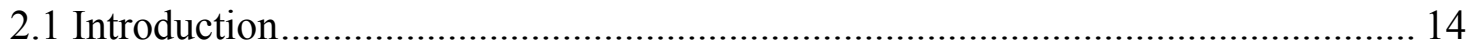

2.2 Measures of Perceived Bicycle Safety............................................................. 14

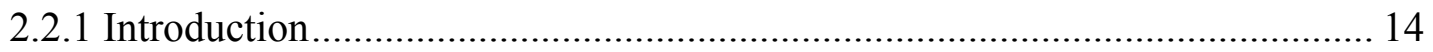

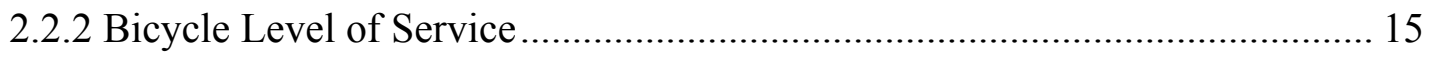

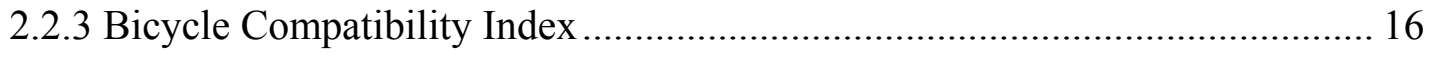

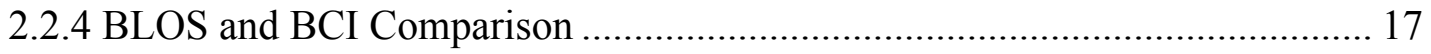


2.3 Development of the Bicycle Network Analysis Tool .......................................... 18

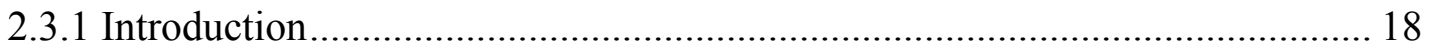

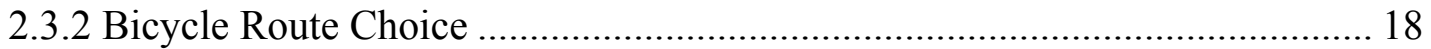

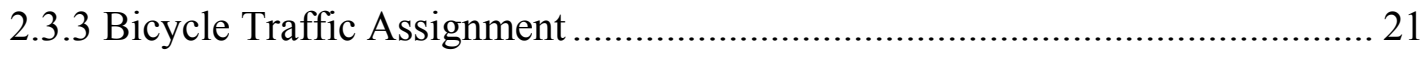

2.3.4 Bicycle Network Analysis Tool Outputs .................................................. 23

2.4 Bicycle Network Analysis Tool Case Study...................................................... 23

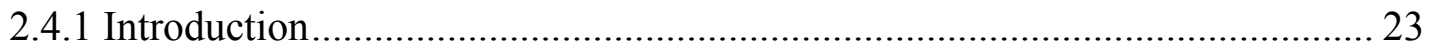

2.4.2 Data Acquisition and Existing Network ..................................................... 24

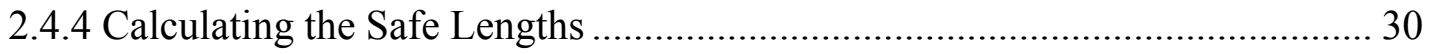

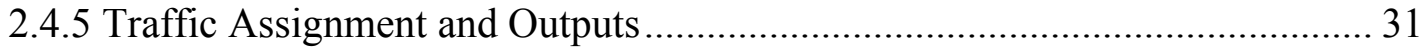

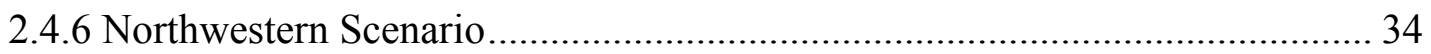

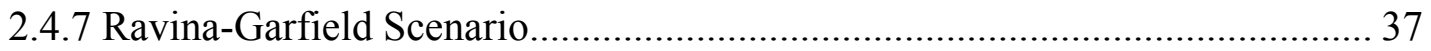

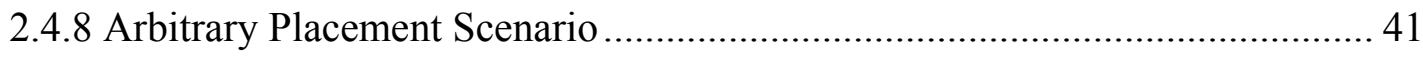

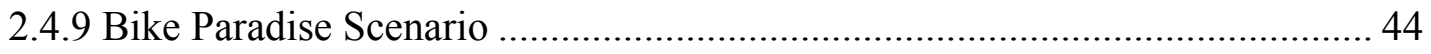

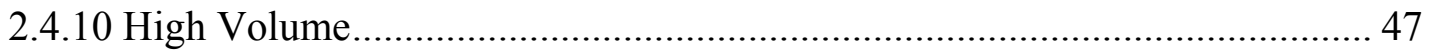

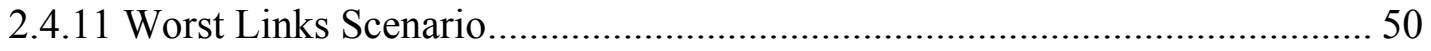

2.4.12 Addition of Specific Trip Generators ................................................... 53

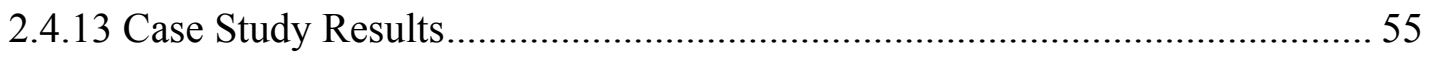

2.5 Conclusions and Future Research................................................................ 57 


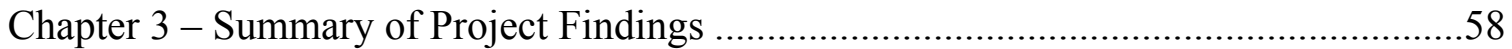

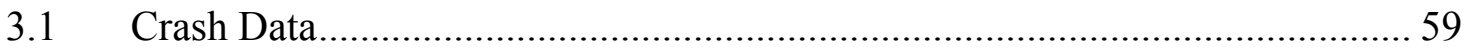

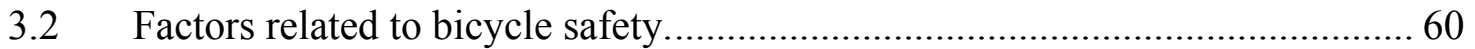

3.3 Bicycle Network Analysis .................................................................... 61

3.4 Study Advisory Committee Recommendations.......................................... 62

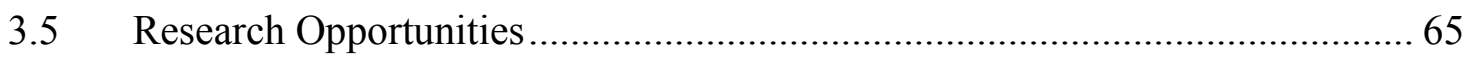

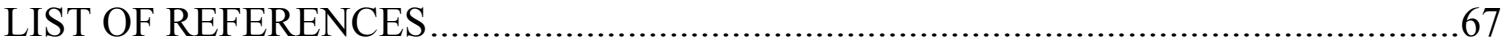




\section{LIST OF TABLES}

Table

Page

Table 1: Top Five Counties by Crash Rate ..................................................................... 7

Table 2: Top Five Counties by Number of Crashes ..................................................... 7

Table 3: Bicycle Level of Service Equation and Factors........................................... 16

Table 4: Bicycle Compatibility Index Equation and Factors ..................................... 17

Table 5: Safe Length Calculations for Route Choice Example .................................... 20

Table 6: Default Values by Roadway Classification for Case Study ............................ 25

Table 7: Shortest Paths for O-D Table Determination Example .................................. 29

Table 8: Origin-Destination Table for O-D Table Determination Example..................... 30

Table 9: BCI of Roads Selected for Improvement in Worst Links Scenario................... 50

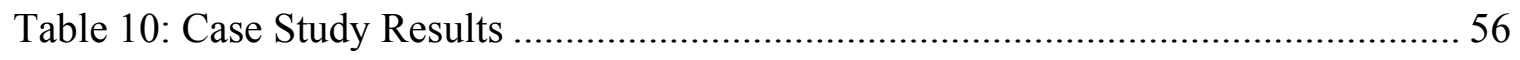




\section{LIST OF FIGURES}

Figure

Page

Figure 1: Bicycle Related Crashes by Junction Involvement ...................................... 3

Figure 2: Bicycle Related Crashes by Collision Type ............................................... 3

Figure 3: Bicycle Related Crashes in Indiana by Primary Cause .................................. 4

Figure 4: Bicycle Related Crashes by Lighting Condition ....................................... 4

Figure 5: Yearly Crash Rates per 100,000 Residents for Indiana Counties ..................... 6

Figure 6: Bicycle Crashes in Indiana by Age and Sex............................................. 8

Figure 7: Bicycle Related Crashes by Month in Indiana ......................................... 8

Figure 8: Network Map for Route Choice Example ................................................. 20

Figure 9: Route Chosen in Bicycle Route Choice Example ....................................... 21

Figure 10: West Lafayette Speed and Traffic Flow Map ......................................... 26

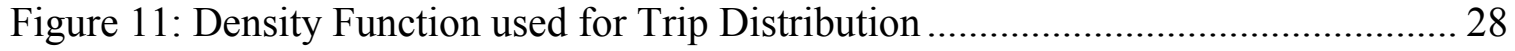

Figure 12: Example Network: Case Study Origin-Destination ................................... 29

Figure 13: Bicycle Flow Map for the Existing Facilities in West Lafayette ................... 33

Figure 14: Existing Bike Lanes in West Lafayette ..................................................... 34

Figure 15: Northwestern Case Bike Lanes ............................................................... 36

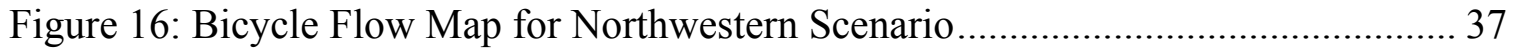

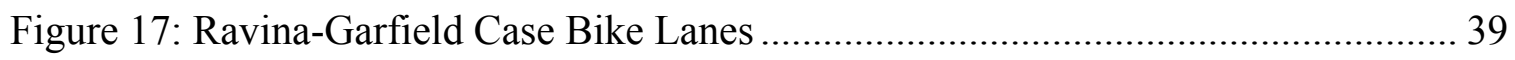


Figure

Figure 18: Bike Flow Map for Ravina-Garfield Scenario ......................................... 40

Figure 19: Arbitrary Placement Case Bike Lanes.................................................. 42

Figure 20: Bike Flow Map for Arbitrary Placement Scenario...................................... 43

Figure 21: Bike Paradise Case Bike Lanes ............................................................... 45

Figure 22: Bike Flow Map for Bike Paradise Scenario ............................................ 46

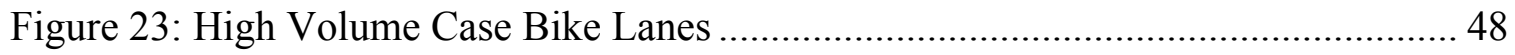

Figure 24: Bike Flow Map for High Volume Scenario ............................................. 49

Figure 25: Worst Links Case Bike Lanes ................................................................ 51

Figure 26: Bike Flow Map for Worst Links Scenario .......................................... 52

Figure 27: Bike Flow Map with Specific Trip Generator Locations ............................. 54

Figure 28 US231 South of SR26 $\ldots . .64$ 


\section{Chapter 1 - Bicycle Crash Analysis}

\subsection{Introduction}

The main purpose of this bicycle crash analysis was to determine potential geometric issues which may cause added danger to bicyclists. This analysis included the investigation of a database of bicycle related crashes in Indiana occurring between 2003 and 2005 , as well as a more thorough look at fatal crash reports in Indiana involving bicyclists, and bicycle related crashes in Tippecanoe County.

\subsection{Statewide Crash Analysis}

\subsubsection{Statewide Bicycle Crash Data Acquisition}

A database containing information on 2,947 crashes that occurred between 2003 and 2005 in Indiana involving bicyclists was obtained from the Center for the Advancement of Transportation Safety (CATS). The database included much of the information provided by the crash reports, such as the date, location, lighting conditions, and pavement conditions. The information in this database was used to investigate possible common factors in these crashes.

\subsubsection{Bicycle Crash Characteristics}

The distribution of bicycle crash locations is shown in Figure 1. Intersections proved to be the most hazardous location for bicycles. Of the 2,947 bicycle related crashes in the statewide database, 1,656 occurred at an intersection. Figure 2 shows the distribution of 
collision types found in the crash database. Over half of all bicycle related collisions were right angle crashes, suggesting that many crashes occur in situations in which visibility is an issue. The bicyclist may have appeared in front of the vehicle without sufficient time for the motorist to react. This also gives further indication that intersections are the most dangerous locations for bicyclists, providing evidence that extra precaution should be taken to ensure bicycle visibility on the approaches. One hundred forty two crashes involving bicyclists occurred in school zones. The high volumes of bicycle and motor vehicles traveling through school zones at the beginning and end of the school day create potentially dangerous situations. Efforts to increase safety near schools by designating specific bike routes or further lowering vehicle speeds may help reduce this number. The motorist fled the scene of the accident in nearly $15 \%$ of the bicycle related crashes in the database. Hit and run accidents are very dangerous, because those injured may not receive the medical care they require as quickly as they need it. The majority of bicycle related crashes were attributed to actions of either the driver or bicyclist, according to the reporting officer, as seen in Figure 3 (the term "pedestrian action" encompasses pedestrians and bicyclists). This does not provide much evidence of circumstances common in bicycle crashes, and does not provide any insight into potential improvements that could be made to bicycle facilities to reduce collisions. The large number of crashes that list their primary factor as "failure to yield" reiterates the idea that low visibility or awareness of bicyclists is a common cause of bicycle related crashes. A large majority of bicycle related crashes occur during the daytime (Figure 4), showing that these crashes may be caused by roadway geometry. 


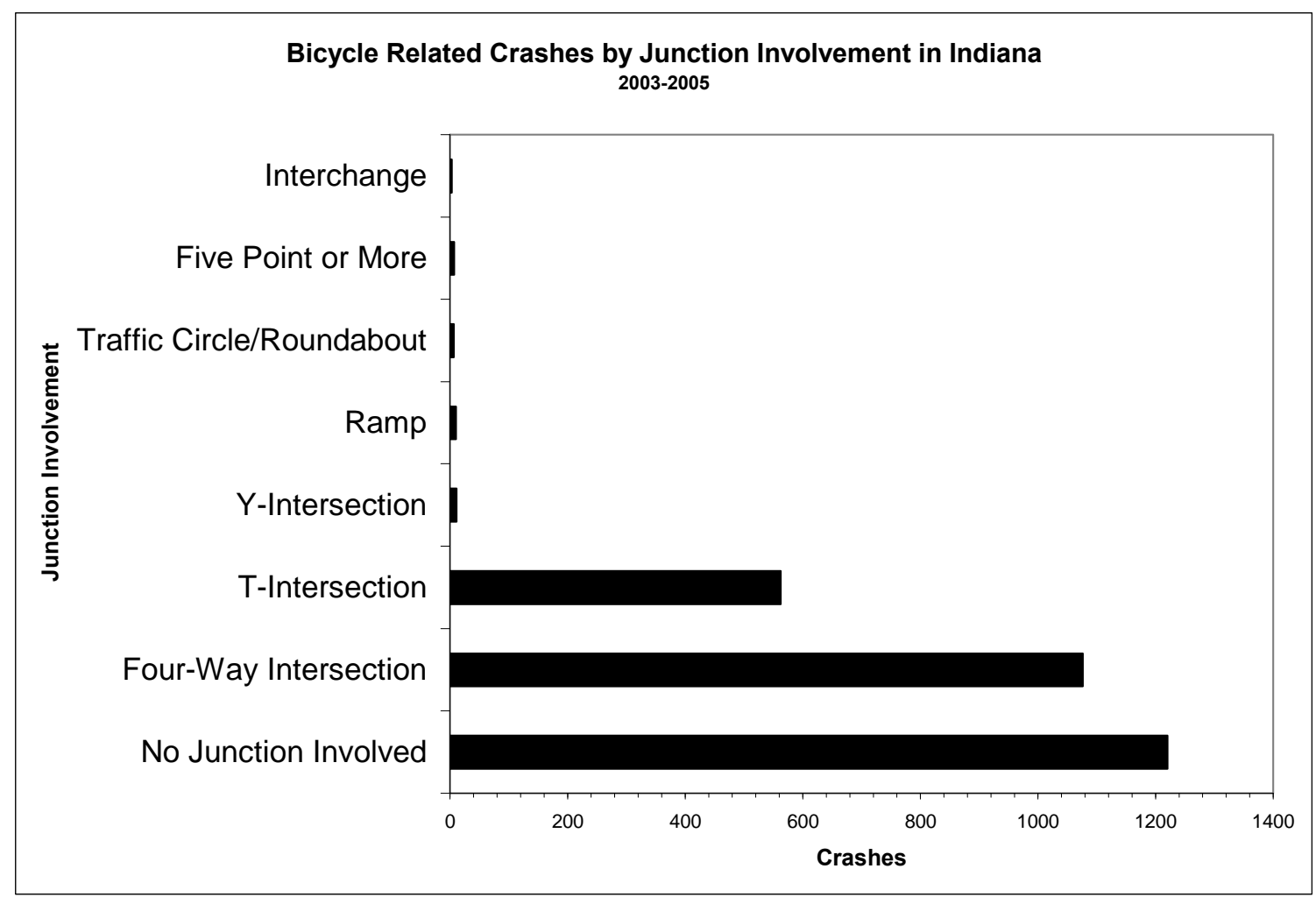

Figure 1: Bicycle Related Crashes by Junction Involvement

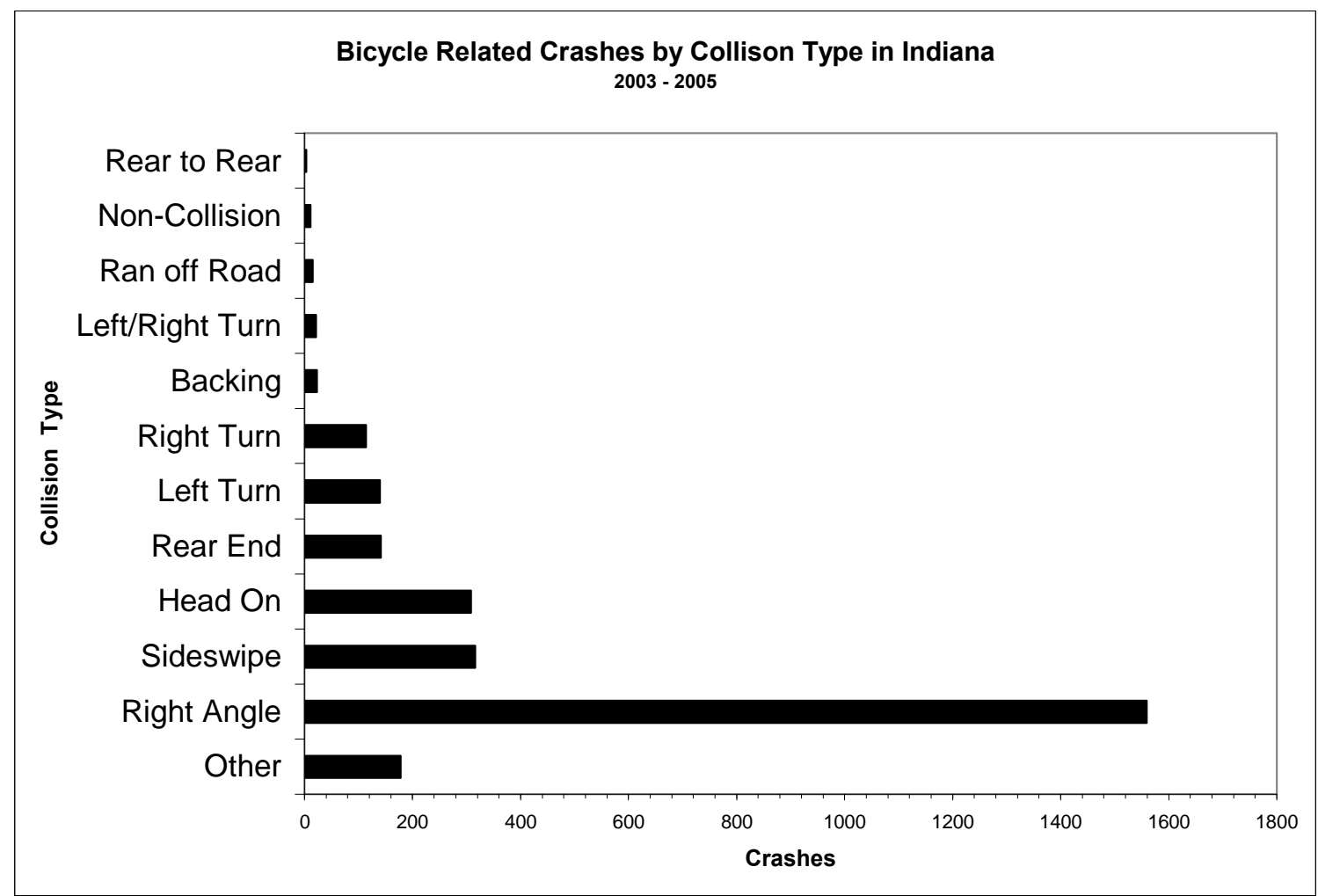

Figure 2: Bicycle Related Crashes by Collision Type 


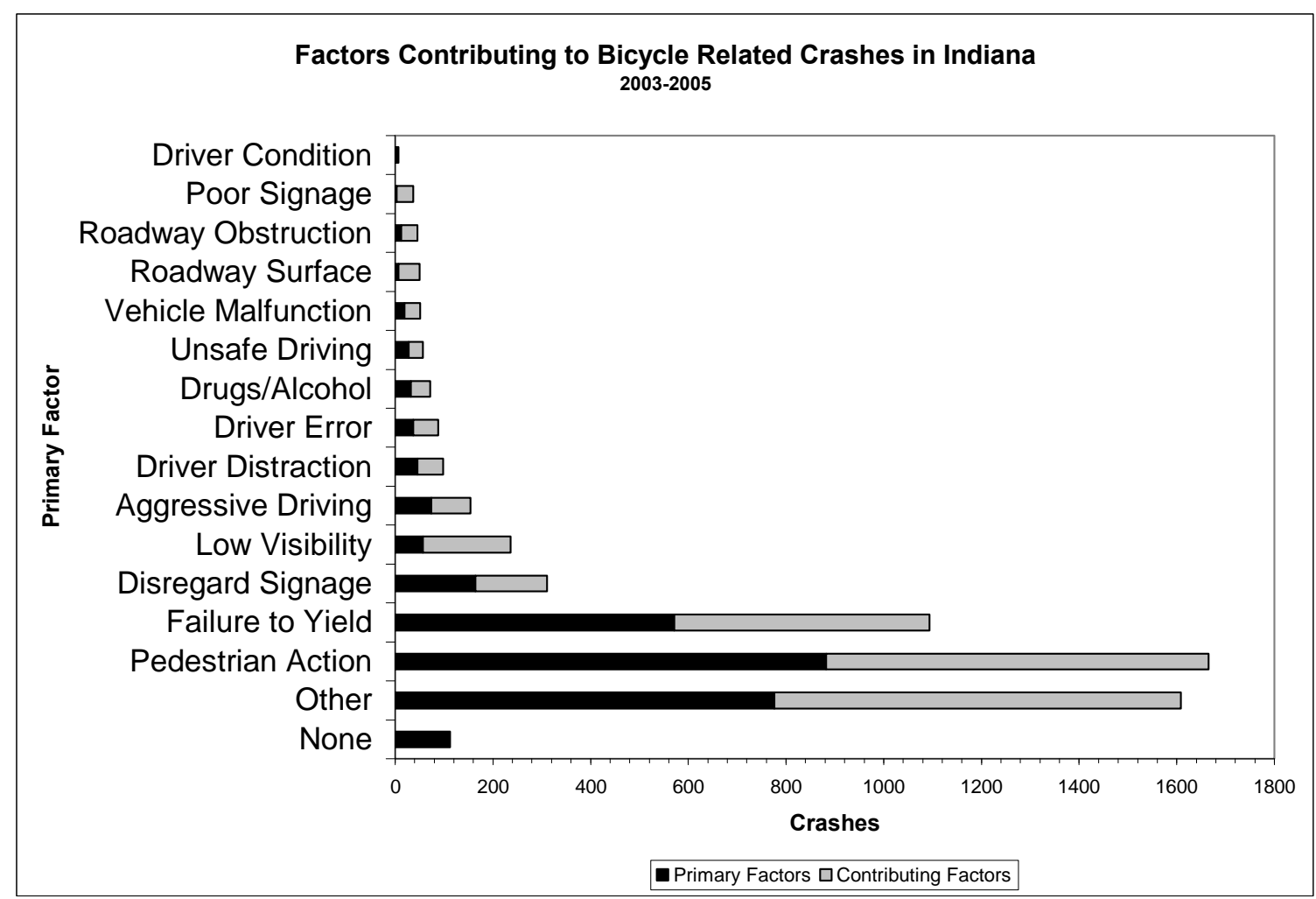

Figure 3: Bicycle Related Crashes in Indiana by Primary Cause

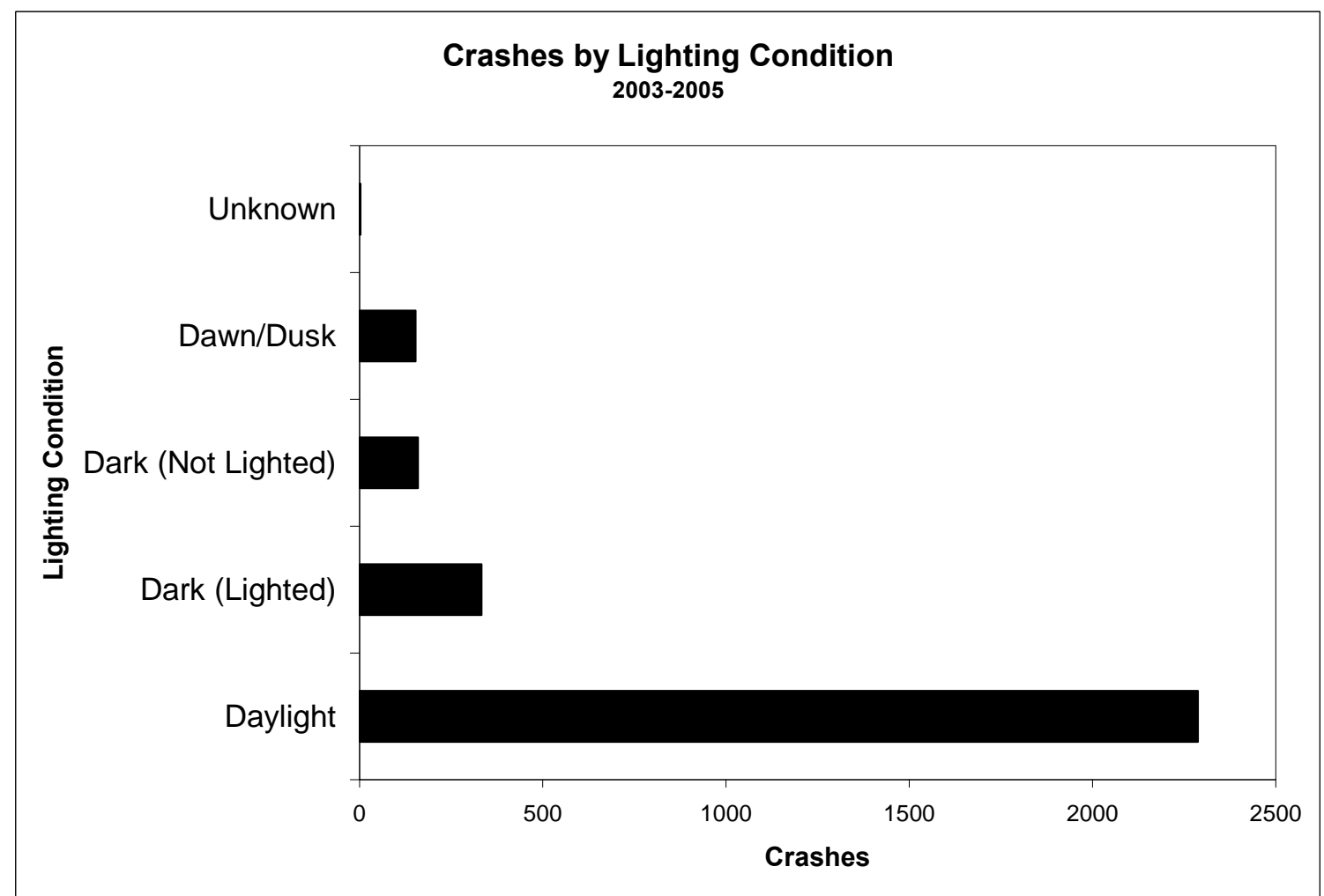

Figure 4: Bicycle Related Crashes by Lighting Condition 


\subsubsection{Bicycle Crash Demographics}

Figure 5 shows the bicycle crash rate of each county in Indiana per year per 100,000 residents according to the 2000 census. The counties with the five highest crash rates and the statewide rate can be seen in

Table 1. Vigo County and Elkhart County are of particular interest due to their high populations. Attempts to increase safety in these areas may be the most efficient use of funds. Marion County expectedly had the highest number of crashes in the state (Table 2), because it is the most populous county in the state. The database revealed some interesting characteristics of bicycle related crashes. $61 \%$ of the bicyclists injured in crashes were under the age of 20 , as seen in Figure 6 . Over $76 \%$ of all bicyclists injured in Indiana were males. Exposure data is necessary to determine a crash rate for these demographics. The relative number of crash rates with respect to the amount of bicycle travel would provide information on the level of risk taken by riders in each group. Without the exposure data, the numbers indicate that males younger than 20 years old are those at the greatest risk of being involved in a bicycle related crash. The monthly variation in crashes follows an expected pattern, as seen in Figure 7. The number of crashes increases as the weather becomes more conducive to bike riding during the spring, plateaus over the summer months, and tails off with the onset of winter. 


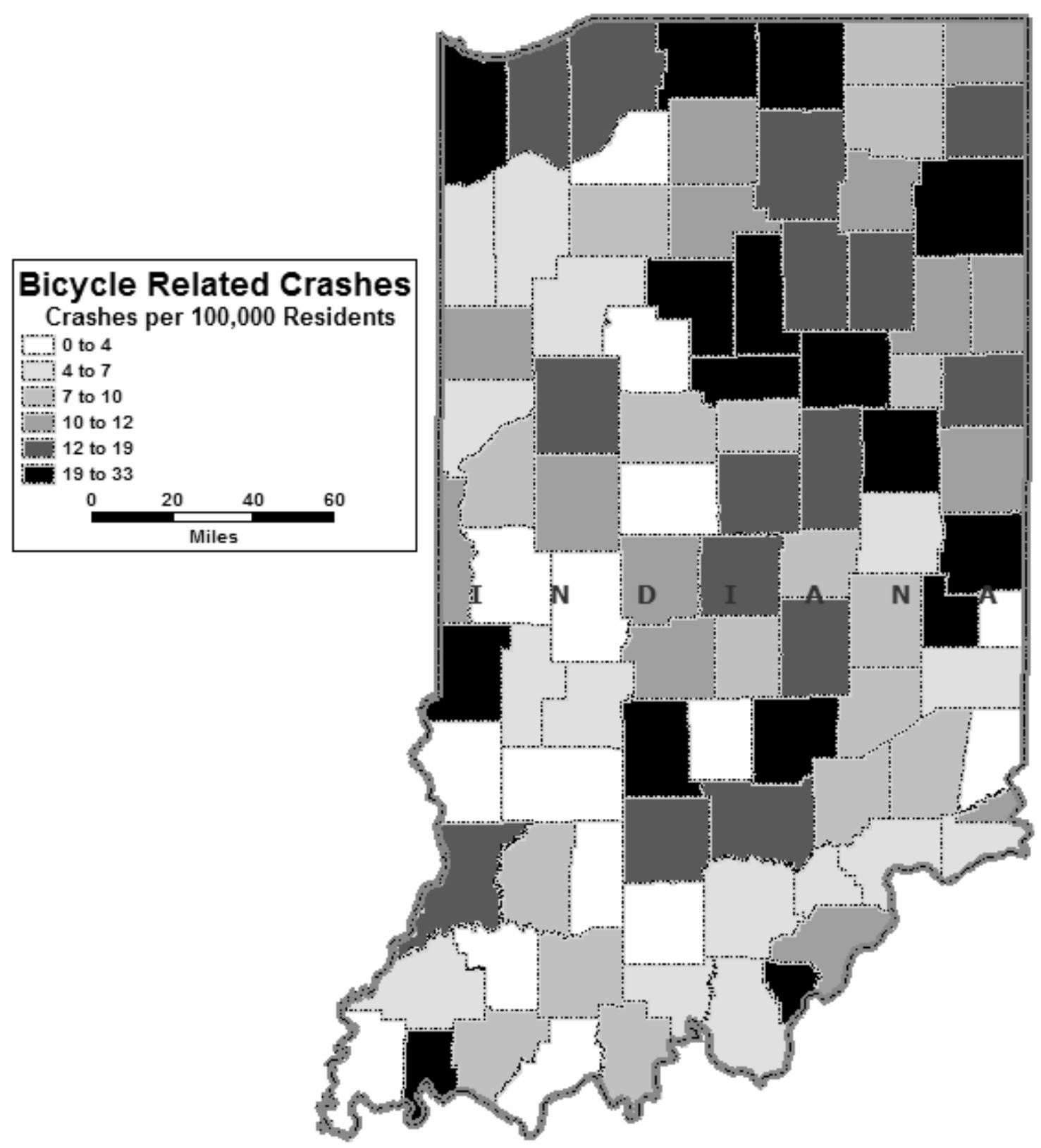

Figure 5: Yearly Crash Rates per 100,000 Residents for Indiana Counties 
Table 1: Top Five Counties by Crash Rate

\begin{tabular}{|c|c|c|}
\hline County & $\begin{array}{c}\text { Crashes Between } \\
\text { 2003-2005 }\end{array}$ & $\begin{array}{c}\text { Crashes per } \\
\text { year per } \\
100,000 \\
\text { Residents }\end{array}$ \\
\hline Vigo & 104 & 32.75 \\
\hline Elkhart & 166 & 30.27 \\
\hline Fayette & 23 & 29.96 \\
\hline Miami & 31 & 28.64 \\
\hline Wayne & 54 & 25.32 \\
\hline All & 2,947 & 16.16 \\
\hline
\end{tabular}

Table 2: Top Five Counties by Number of Crashes

\begin{tabular}{|c|c|c|}
\hline County & $\begin{array}{c}\text { Crashes Between } \\
2003-2005\end{array}$ & $\begin{array}{c}\text { Crashes per } \\
\text { year per } \\
100,000 \\
\text { Residents }\end{array}$ \\
\hline Marion & 461 & 17.86 \\
\hline Lake & 286 & 19.67 \\
\hline Allen & 206 & 20.69 \\
\hline St. Joseph & 197 & 24.73 \\
\hline Elkhart & 166 & 30.27 \\
\hline
\end{tabular}




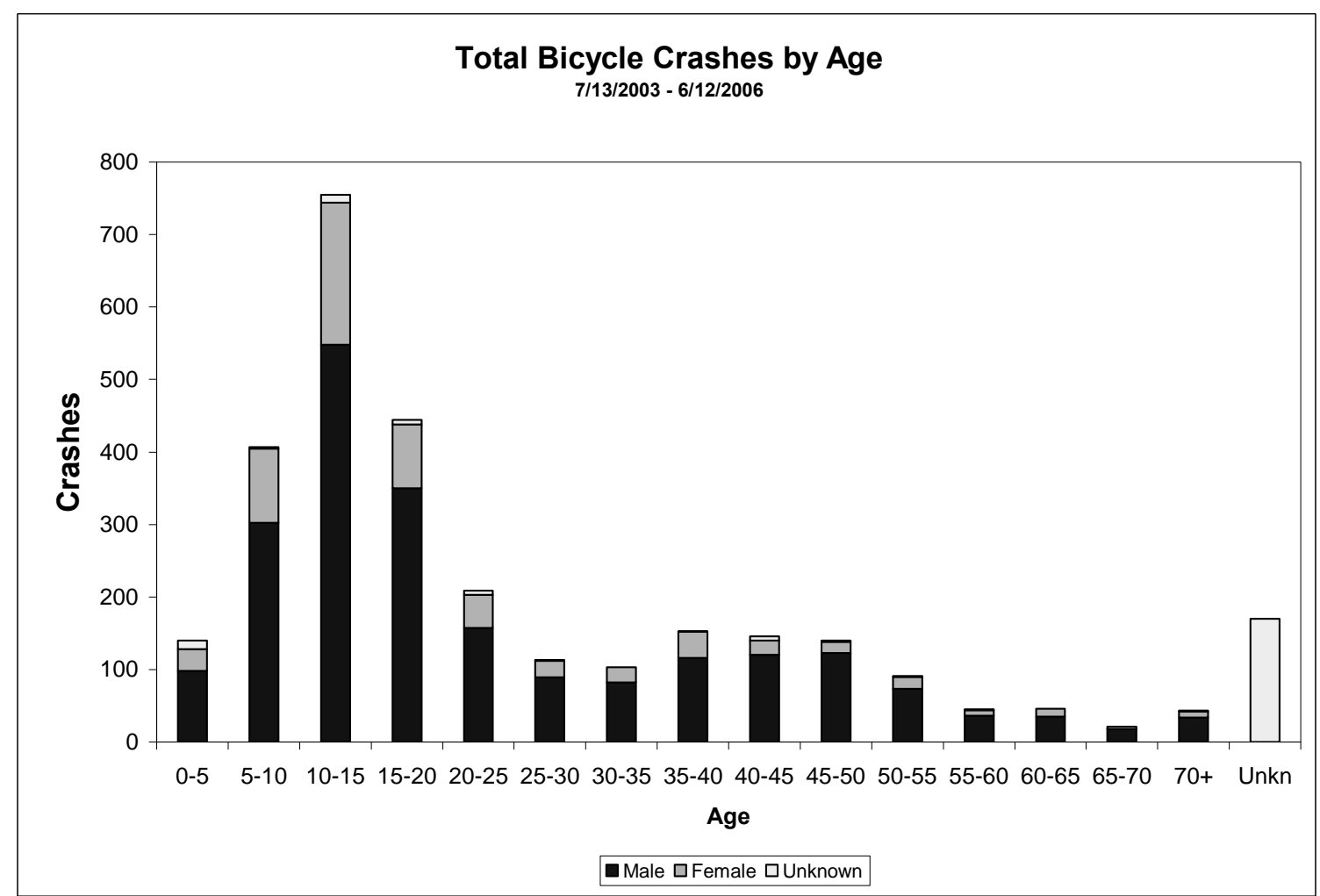

Figure 6: Bicycle Crashes in Indiana by Age and Sex

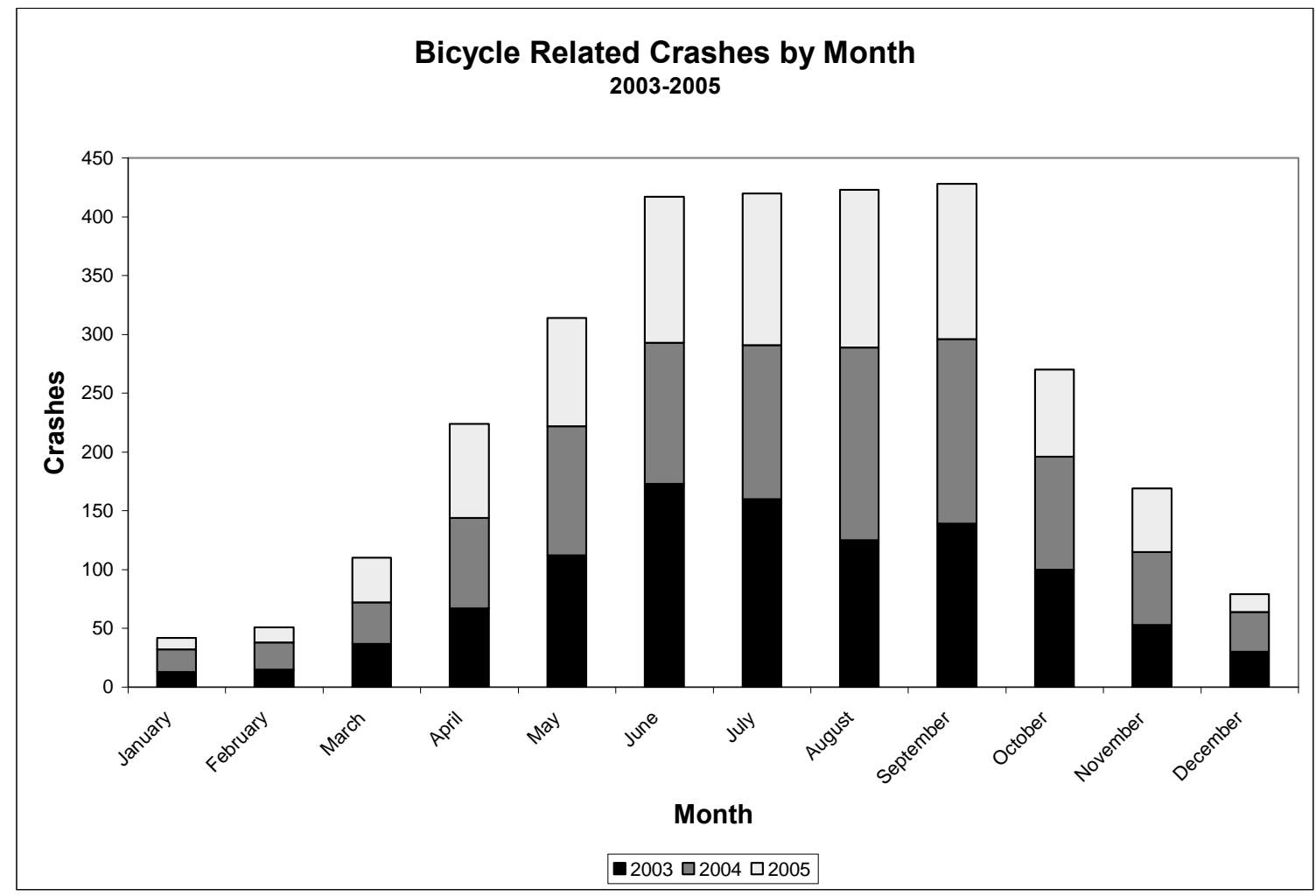

Figure 7: Bicycle Related Crashes by Month in Indiana 


\subsubsection{Bicycle Crash Database Limitations}

While the bicycle crash database is a helpful tool that can be used to summarize common factors of bicycle crashes, it lacked some desirable information. Age and sex information was only available for those injured in the crashes, leaving 170 cyclists' information unavailable, as they were uninjured in the collision. The database lacks descriptions and narratives for each crash, leaving ambiguities in the analysis of the factors causing the crash. The term "pedestrian action," does not differentiate between cyclists and pedestrians, despite the large differences of the two groups. While the crash report for each individual incident can be obtained, it is a cumbersome process to print paper copies and use the crash reports to extract information. The lack of exposure data reduces the usefulness of aggregate crash data; however the investigation of the characteristics of bicycle crashes still has value.

\subsection{Crash Report Analysis}

A sample of crash reports involving bicyclists obtained from Keth Sapp at CATS was investigated to determine of the circumstances leading to collisions. The sample included all bicycle crashes in Indiana between 1/1/2004 and 11/21/2005, as well as all injury and PDO crashes during the same period in Tippecanoe County. A total of 61 reports were examined, including 23 fatal crashes, 29 injury crashes, and 9 PDO crashes. The eight of the fatal bicycle crashes in Indiana were attributed to cyclist error in the crash reports, and in three the driver fled the scene. Incidents involving cyclists illegally crossing roads, accepting inadequate gaps, disregarding signage were present. 12 fatal crashes occurred at night. Poor lighting was a significant factor in 10 of the 23 fatal crashes. This provides 
evidence that nighttime crashes are more likely to result in fatalities than those during daylight hours, because many more crashes occur during the day (Figure 4). The most common causes of injury and PDO crashes in Tippecanoe County were vehicles making permitted left turns while cyclists were traveling through the intersection from the opposite approach, or cyclists illegally traveling on the sidewalk. These crashes can be partially attributed to motorists' lack of consideration to possible bicycle traffic when making decisions. A motorist making a permitted left turn may not scan the oncoming lane, unaccustomed to the presence of bicyclists. Vehicles entering and exiting from driveways are unable to anticipate cyclists illegally traveling on the sidewalk, causing several accidents.

The information provided in the reports had some variation. The format of the reports was not uniform, and some information, including crash diagrams and crash descriptions, was missing from several reports due to officer omission, or because of the format of the report. 


\subsection{Bicycle Crash Conclusions and Future Research}

One purpose of this study was to identify factors that are present in crashes involving bicycles and bicyclist. In the process, several problems or shortcomings with the available data have been encountered. They are listed below, along with suggestions for work that could be done during more extensive or specialized studies.

- Without exposure rates, it is difficult to determine the relative risk taken by bicyclists in particular demographics or geographic locations. Some sort of survey effort should be undertaken to begin the acquisition of data on the extent to which bicycles are used. The number and length of bicycles, broken down by the age and sex of bicyclists, would permit the conversion of total crashes into bicycle crash rates, and permit the creation of focused countermeasures.

- This report has identified counties that experience an unusually high number of crashes. Likewise, counties with a high crash rate (crashes per 100,000 residents) have been identified. These counties represent good locations for a detailed study of individual crash reports, to investigate whether certain factors are contributing to these high values.

- This study has found a high crash rate for young male bicyclists. Using exposure data or a detailed look at crash reports, these issues should be further investigated to determine whether the high crash numbers are symptomatic of dangers faced by these particular riders.

- By far the most common type of crash involving bicyclists and motor vehicles is a right angle crash. A study of crash reports involving right angle crashes is needed to 
clarify the circumstances under which these collisions occurred. Only then can countermeasures to reduce this type of collision be proposed.

- Bicycle crashes are generally thought to be greatly underreported. One reason is that the minimum value of property damage that requires that the incident be reported is \$750. Another reason for underreporting is that bicycle-only incidents do not appear in the standard crash data bases. Incidents must involve a motor vehicle to be reported. Furthermore, no crashes on bike paths were reported in the database.

- Changes to the format of the crash reporting form completed on the scene by police would benefit bicycle safety research. Bicyclists are included in the "Pedestrian" category in the "contributing factor" portion of the form. A bicyclist-specific option would help identify factors regarding bicyclists. In addition, it would be very helpful for bicycle safety research to have provisions on the crash reporting form to note whether the bicyclist was wearing a helmet, wearing bright or reflective clothing, and operating a bicycle at night with lights or reflectors.

There is little evidence from the detailed analysis of a sample of crash reports suggesting that significant changes in roadway design or public policy are warranted. The enforcement of city sidewalk ordinances would likely reduce the number of incidents between bicyclists and motor vehicles by forcing cyclists to ride on streets, bike lanes, and paths, where motorists are more likely to expect them. At the same time, the addition of signs, painted bike lanes, or shared-use lane markings are needed to encourage bicyclists to use roadways instead of sidewalks. The most prominent danger determined 
in this research is the low visibility of bicyclists at night. The high proportion of fatal crashes occurring in dark conditions indicates that bicyclists must take steps to improve their visibility. 


\section{Chapter 2 - Bicycle Network Analysis Tool}

\subsection{Introduction}

The Safe Accountable Flexible Transportation Equity Act (SAFETEA-LU) has created a new source of funding for the construction of bicycle facilities. It is incumbent upon local agencies to make efficient use of these funds to create the largest possible increase in the quality of life for their residents. The construction of a safe, well-connected bicycle network can enhance the safety and health of children and adults, as well as converting trips from automobiles, thereby reducing the strain on the environment. To make proper decisions and implement effective changes to the bicycle network, a method of evaluation must be developed. The Bicycle Network Analysis Tool (BNAT) developed in this report is intended to fill this void, and provide a way to determine the quality of an existing bicycle network, as well as serve as an investment guide to aid in the efficient use of available funds.

\subsection{Measures of Perceived Bicycle Safety}

\subsubsection{Introduction}

In order to evaluate a network, the individual links in the network must also be evaluated. Currently, there are a number of evaluation tools available that can be used to quantify user perception of roadway facilities with respect to bicycling. The two tools most commonly used to quantify the perceived safety of a bicycle facility are the Bicycle 
Compatibility Index (BCI), and the Bicycle Level of Service (BLOS). While Level of Service (LOS) measures for automobiles are based on simple traffic flow properties, such as density or delay, the BCI and BLOS are more complicated regression models using several properties of bicycle facilities.

\subsubsection{Bicycle Level of Service}

In 1997, Sprinkle Consulting Engineers, Inc. developed the BLOS (Landis et al., 1997). Bicyclists rode on a specified route and rated the safety of each link at checkpoints along the route. A model was then developed using linear regression to predict the responses using the properties of each segment. Table 1 shows the descriptive variables used in the model. 


\section{Table 3: Bicycle Level of Service Equation and Factors}

$$
\operatorname{BLOS}=\mathrm{a}_{1} \ln \left(\mathrm{Vol}_{15} / \mathrm{L}\right)+\mathrm{a}_{2} \ln \left[\mathrm{SPD}_{\mathrm{p}}(1+\mathrm{HV} \%)\right]+\mathrm{a}_{3} \ln \left(\mathrm{COM}_{15} * \mathrm{NCA}\right)+\mathrm{a}_{4}\left(\mathrm{PC}_{5}\right)^{-2}+\mathrm{a}_{5}(\mathrm{We})^{2}+\mathrm{C}
$$

- $B L O S=$ perceived hazard of the shared- $\quad C O M_{15}=$ trip generation intensity of the land use roadway environment,

- $\quad \operatorname{Vol}_{15}=$ volume of directional traffic in 15min time period,

- $L=$ total number of through lanes, adjoining the road segment (stratified to a commercial trip generation of 15 , multiplied by the percentage of the segment with adjoining commercial land development),

- $S P D_{p}=$ posted speed limit (a surrogate for average running speed),

- $H V \%=$ percentage of heavy vehicles (as defined in the Highway Capacity Manual),

- $N C A=$ effective frequency per mile of uncontrolled vehicular access (e.g., driveways and on-street parking spaces),

- $\mathrm{C}=$ Constant $P C_{5}=$ FHWA's 5-point pavement surface condition rating, and

- $W_{e}=$ average effective width of outside through lane $\left(W_{e}=W_{t}+W_{l}-W_{r}\right.$, where $W_{t}=$ total width of outside lane (and shoulder) pavement, $W_{l}=$ width of paving between the outside lane stripe and the edge of pavement, and $W_{r}=$ effective width (reduction) due to encroachments in the outside lane.)

\subsubsection{Bicycle Compatibility Index}

The BCI was developed for the Federal Highway Administration by the Highway Safety Research Center at the University of North Carolina (Harkey et al., 1998). Mid-block roadway segments with varying geometry and traffic conditions were videotaped, and viewed by a diverse group of bicyclists. The bicyclists then rated their perceived safety of the segments. A linear regression model was then developed using geometric properties and traffic conditions as predictors of the bicyclists' ratings. Table 2 shows the equation and a description of the variables used to calculate the BCI. 
Table 4: Bicycle Compatibility Index Equation and Factors

$$
\mathrm{BCI}=\mathrm{C}-\mathrm{a}_{1} \mathrm{BL}-\mathrm{a}_{2} * \mathrm{BLW}-\mathrm{a}_{3} \mathrm{CLW}+\mathrm{a}_{4} \mathrm{CLV}+\mathrm{a}_{5} \mathrm{OLV}+\mathrm{a}_{6} \mathrm{SPD}+\mathrm{a}_{7} \mathrm{PKG}-\mathrm{a}_{8} \mathrm{AREA}+\mathrm{AF}
$$

- $B L=$ Presence of a Bicycle Lane or Paved - $P K G=$ Presence of a Parking Lane With More Shoulder Than $30 \%$ Occupancy

- $\quad B L W=$ Bicycle Lane or Paved Shoulder - $A R E A=$ Presence of Residential Roadside Width

- $\quad C L W=$ Curb Lane Width Development

- $\quad C L V=$ Curb Lane Volume

- $O L V=$ Other Lane Volume

- $A F=\mathrm{f}_{\mathrm{t}}+\mathrm{f}_{\mathrm{p}}+\mathrm{f}_{\mathrm{n}}$

- $S P D=85$ th Percentile Speed of Traffic

- $f_{t}=$ Adjustment Factor for Truck Volumes

- $f_{p}=$ Adjustment Factor for Parking Turnover

- $\mathrm{C}=$ Constant

- $f_{n}=$ Adjustment Factor for Right Turn Volumes

\subsubsection{BLOS and BCI Comparison}

Each evaluation tool was developed using cyclists' stated perception of the conditions faced by a bicyclist on various facilities, and using the properties of the facility and its environment to fit a linear regression to predict these perceptions. The BCI and BLOS regressions share several common variables: adjacent traffic volume, adjacent traffic speed, bike lane or curb lane width, a heavy vehicle factor, parking and driveway frequency, and a value relating to adjacent land use. Neither model requires the use of bicycle volumes, because bicycle facilities rarely approach capacity and bicycle counts are not typically available. The BCI is a simpler model, because the BLOS requires the acquisition of more detailed land use and pavement condition information. Both models require a large amount of information, each implementing approximately ten variables. The large number of variables increases the difficulty of using either tool to describe the compatibility of each link in a large network, reducing their usefulness for a large bicycle network. 


\subsection{Development of the Bicycle Network Analysis Tool}

\subsubsection{Introduction}

To accurately represent the benefit gained from the improvement or construction of a bicycle facility, it is necessary to determine the impact on the bicycle network as a whole. The effect of a bicycle facility improvement will vary depending on the importance of the link. In order to quantify the system-wide effect of changing network properties a method to determine the level of safety of a network is needed. The BNAT developed in this study attempts to fill that need, and provide evidence to aid in investment decisions. While providing connectivity is valuable to those who ride for leisure and commuters, this tool focuses on enabling safe trips for commuters.

\subsubsection{Bicycle Route Choice}

The network measure is path based. In order to identify the path that a bicyclist would be expected to travel from origin to destination, it is necessary to quantify the evaluation criteria a bicyclist may use to select a route. For automobile trips, travel time is the most practical predictor of user preference. This method makes a reasonable assumption: all roads in the network are safe for automobiles, leaving travel time as the principal characteristic for route choice. For bicyclists, however, this assumption is not as valid. High volume and high speed roadways without bike lanes or wide shoulders deter many bicyclists from taking the shortest path. A bicyclist likely considers the difference in safety between the possible routes from origin to destination. 
For this study, it is assumed that bicyclists make decisions based on two factors: perceived safety, which can be modeled by the BCI, and travel distance. While other variables, such as grade or aesthetics, may affect the attractiveness of a route, safety and travel time are expected to be the two most important considerations. The bicyclist's perceived cost of each link in the network can be defined as the product of the link length and its BCI. This cost is named the "Safe Length" of the link. Each mile of Safe Length is called a Safe mile (smi), to differentiate between the actual distance and the adjusted distance. While this is a crude way to weight the links, it does provide a reasonable estimation of a bicyclist's thought process. As length increases, the Safe Length also increases, incorporating the actual trip length and the increased exposure. As the perceived safety of a link decreases, the BCI increases, causing the Safe Length to increase. Long, unsafe links are less attractive than short, safe links according to this method. The sums of the links in each potential path are compared, and the bicyclist chooses the route that minimizes the total Safe Length of the trip. 


\section{Bicycle Route Choice Example}

A bicyclist wants to travel from 1 to 6 in Figure 8. Using the Safe Length criterion, which route will he or she select?

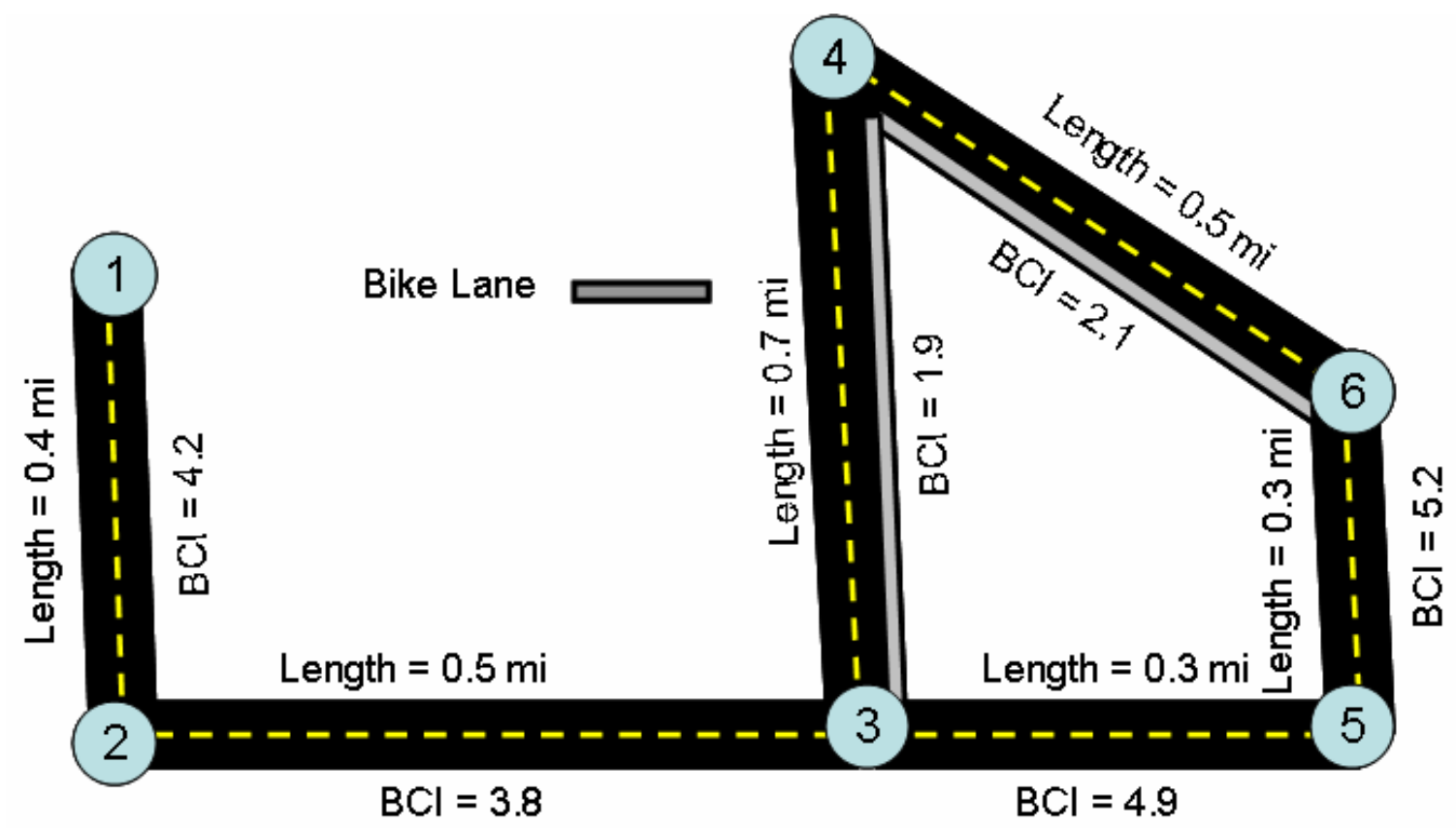

Figure 8: Network Map for Route Choice Example

Table 5: Safe Length Calculations for Route Choice Example

$\begin{array}{lllrlll}\text { Link } & \text { Length (mi) } & \text { BCI } & \text { Length } & * & \text { BCI } & = \\ (1,2) & 0.4 & 4.20 & 0.40 & * & 4.2 & =1.68 \\ (2,3) & 0.5 & 3.80 & 0.50 & * & 3.8 & =1.90 \\ (3,4) & 0.7 & 1.90 & 0.70 & * & 1.9 & =1.33 \\ (3,5) & 0.3 & 4.90 & 0.30 & * & 4.9 & =1.47 \\ (4,6) & 0.5 & 2.10 & 0.50 & * & 2.1 & =1.05 \\ (5,6) & 0.3 & 5.20 & 0.30 & * & 5.2 & =1.56\end{array}$

There are two potential routes, Route A (1-2-3-5-6) and Route B (1-2-3-4-6).

$\underline{\text { Route } A}$

Total Length $_{A}=$ Length $_{1,2}+$ Length $_{2,3}+$ Length $_{3,5}+$ Length $_{5,6}$

$=0.4+0.5+0.3+0.3$

$=1.5 \mathrm{mi}$

Total Safe Length $=$ Safe Length L $_{1,2}+$ Safe Length L $_{2,3}+$ Safe Length L $_{3,5}+$ Safe Length ${ }_{5,6}$ 
$\underline{\text { Route B }}$

$$
\begin{aligned}
& =1.68+1.90+1.47+1.56 \\
& =6.61 \text { Safe miles }
\end{aligned}
$$

Total Length $_{B}=$ Length $_{1,2}+$ Length $_{2,3}+$ Length $_{3,4}+$ Length $_{4,6}$

$$
\begin{aligned}
& =0.4+0.5+0.7+0.5 \\
& =2.1 \mathrm{mi}
\end{aligned}
$$

Total Safe Length L Safe Length $_{1,2}+$ Safe Length L $_{2,3}+$ Safe Length Le $_{3,4}+$

Safe Length 4,6

$=1.68+1.90+1.33+1.05$

$=5.91$ Safe miles

While Route $A$ is shorter than Route B, the bicycle route choice model selects Route B (Figure 9), because it has a lower Total Safe Length.

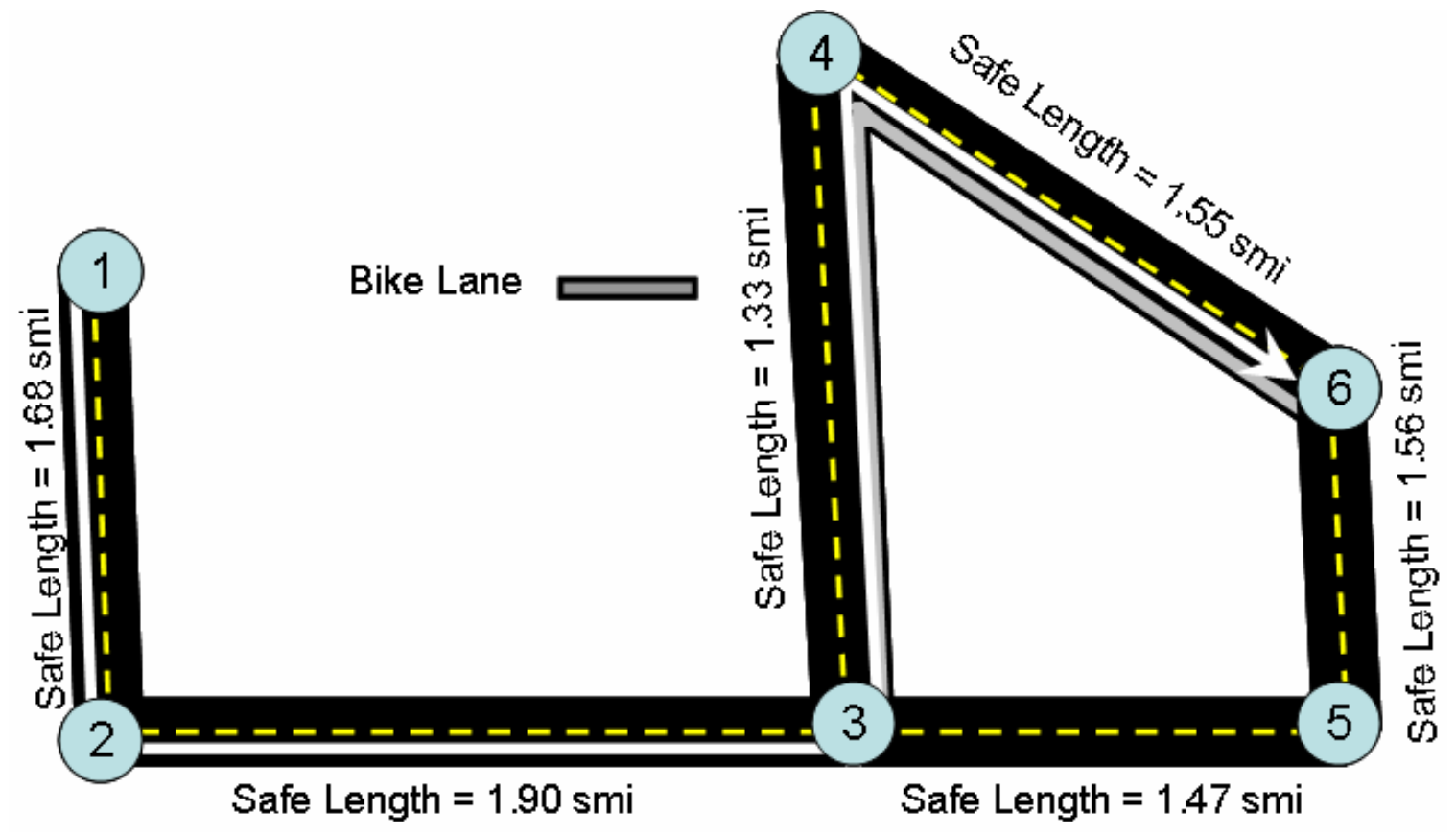

Figure 9: Route Chosen in Bicycle Route Choice Example

\subsubsection{Bicycle Traffic Assignment}

The number of bicycle trips between any two intersections is assigned to the path that minimizes the Safe Length. This is done for each pair of intersections. The Safe Lengths of the resulting paths are weighted by their bicycle volumes and then summed, creating 
an overall value for the network. Creating the origin-destination table to model the demand can be a difficult, labor intensive task. Bicycle volumes are not readily available, and difficult to accurately measure. To overcome this lack of data, an assumed bicycle trip length distribution can be used to predict the demand between nodes. Due to the lack of available information, no actual trip length distribution could be constructed for this report. A simple probability density function can be used in place of an empirical trip length distribution if data cannot be found. In addition to simplifying the procedure, the predicted table based on a probability density function promotes overall network connectivity, rather than the improvement of specific corridors of dense bicycle traffic, providing greater utility to all potential bicyclists. This places added emphasis on the safety of important links on the network. If a trip table or bicycle trip length distribution can be obtained, it can easily be incorporated into the BNAT, providing more accurate results.

An unsafe segment that is the only connection between two areas can cause a severe reduction in network safety, creating a drastic increase in the network measure. The use of a path based method can indicate potential high volume segments, as well as the segments most crucial to the connectivity of the network. The improvement of the bicycle facilities on one roadway, or even one link can have great impact on the overall network safety. Users choose their paths based on the total Safe Length of the route, so significant change in one link can cause bicyclists to divert to the newly renovated facility. 


\subsubsection{Bicycle Network Analysis Tool Outputs}

In order to create an index with which bicycle networks can be compared, it is necessary to scale the overall network value by some network property, such as the number of links, intersections, or total network length. This would allow each network to be compared with any other network, independent of magnitude, providing bicyclists and governments information about the relative safety of riding in their area. The index would also allow the impact of proposed off street bicycle paths to be analyzed. The change in the index due to a proposed improvement can also be used with the cost in order to maximize the safety improvement in the network, by suggesting the most efficient use of available funds. In order to estimate the cost of a bicycle improvement, an internet based cost estimator has been developed by the Pedestrian and Bicycle Information Center (UNC HSRC, 2006).

\subsection{Bicycle Network Analysis Tool Case Study}

\subsubsection{Introduction}

In order to test the usefulness of the tool, a case study was done on a network in West Lafayette, Indiana. This case study included the existing network and six scenarios, each selecting improvements based on different criteria. This helped determine the locations for bicycle facility investments where the improvement will be most beneficial to the bicycle network. This case study is not intended to be used as an actual investment guide, because it does not account for particular trip attractions, such as Purdue University, and the network structure has not been completely checked for accuracy. The case studies are used to demonstrate a method that can be applied to any road network. 


\subsubsection{Data Acquisition and Existing Network}

In applying the BNAT, it is necessary to gather the information for the study area in order to permit the calculation of the Bicycle Compatibility Index. Much of the data used in this case study, including $85^{\text {th }}$ percentile speeds, curb-to-curb road widths, and average daily traffic, was obtained from the City of West Lafayette, and the Indiana Department of Transportation's Annual Average Daily Traffic maps. The traffic volumes were converted to 2006 levels using an annual growth factor of $3 \%$. The remaining necessary values were assigned based on the roadway classification as seen in Table 6 . The default road width per lane was based on common values for similar roads. The $15 \mathrm{ft}$ width of arterial street lanes attempts to account for the width of shoulders or gutters on the roadway, rather than being a default lane width. Parking occupancy was estimated based on knowledge of the area. An adjustment factor of 0.3 was used in the BCI equation due to the low truck traffic on local roads and the lack of parking on arterial streets, providing a comparable value for each. A GIS map of the area was obtained from the Tiger/Line ${ }^{\circledR}$ database provided by the United States Census Bureau.

Figure 10 shows the $85^{\text {th }}$ percentile speed and peak hour volumes of the roadways in the study area. 
Table 6: Default Values by Roadway Classification for Case Study

Default AADT

Default K

Local Collector Arterial

Default Directional Split

Default 85th Percentile Speed (mph)

$355 \quad 3000$

20000

$\begin{array}{lll}0.10 & 0.10 & 0.10\end{array}$

Default Road Width/Lane (ft)

$0.55 \quad 0.55$

0.55

Annual Growth Factor

Current Year

Bike Lane Width (ft)

Parking Lane Width (ft)

25

$10-12 \quad 15$

$3 \% \quad 3 \% \quad 3 \%$

$2006 \quad 2006 \quad 2006$

$4 \quad 4$

$8 \quad 8$

4

8 


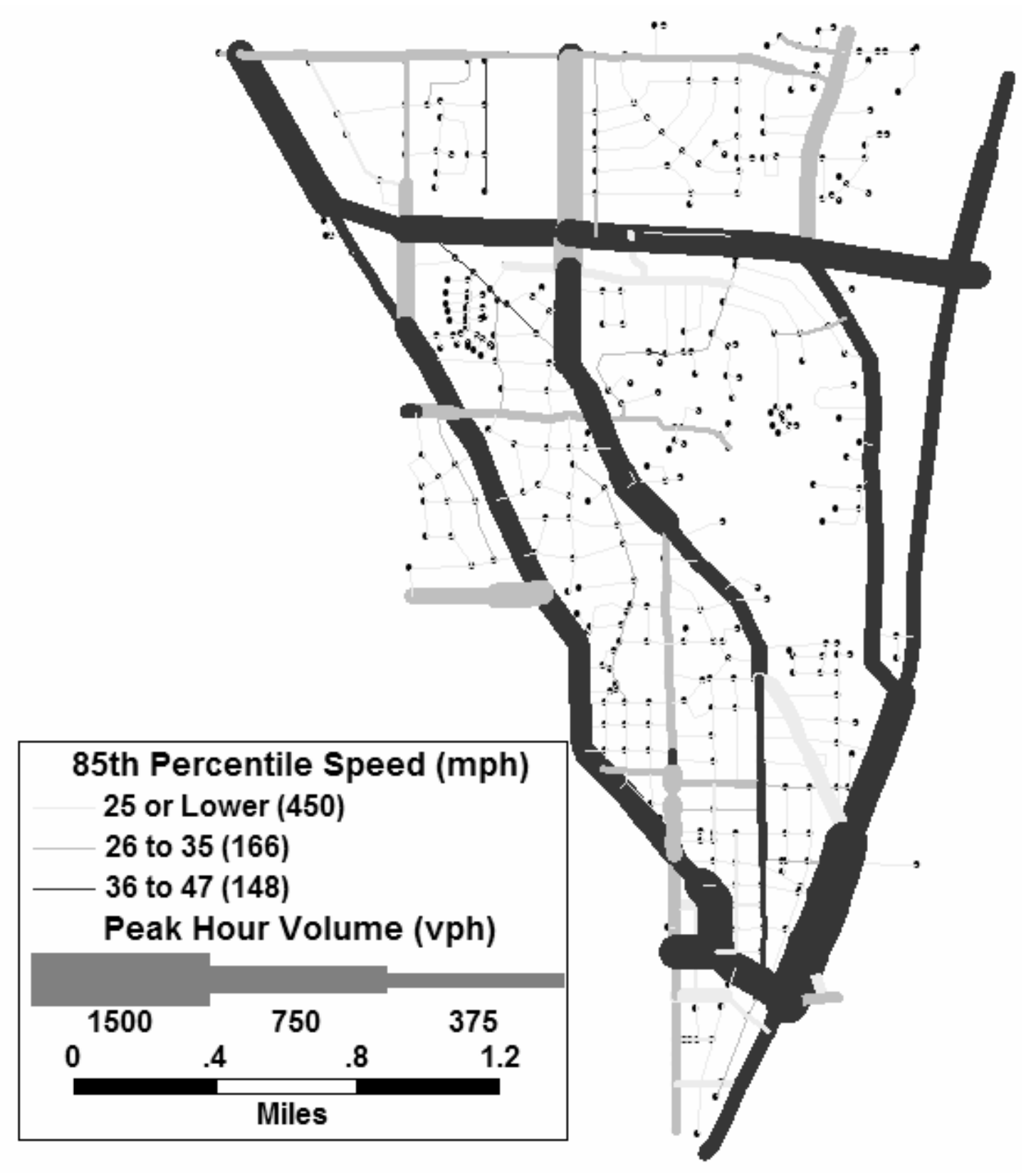

Figure 10: West Lafayette Speed and Traffic Flow Map 


\subsubsection{Creating an Origin-Destination Table}

Bicycle trip length information for the area was unavailable, so it was assumed that the bicycle trip length distribution follows a Gamma distribution, with alpha and beta values of two. The probability density function can be seen in Figure 11. This probability density function provides a reasonable estimation of the relative number of trips between any two nodes. Pairs of close intersections and distant intersections have low trip densities, and trips of approximately two miles are most common. The shortest path distance between the pairs of intersections was used to determine the number of trips to assign. The shortest path distances were found using the "multiple shortest paths" tool in TransCAD. The probability density of each shortest path was then entered into a matrix, forming an origin-destination table. 


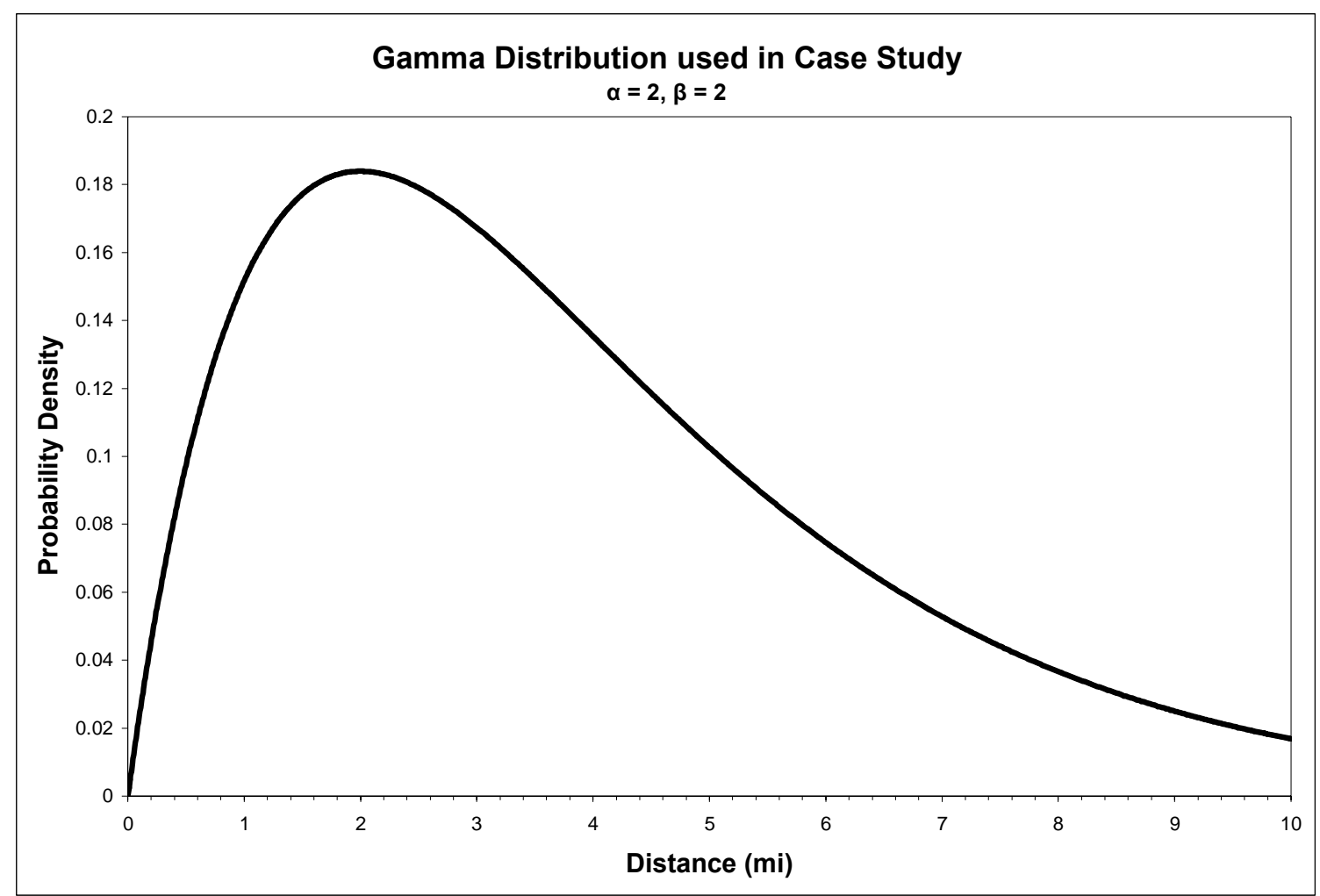

Figure 11: Density Function used for Trip Distribution 


\section{Origin-Destination Table Determination Example}

Create an Origin Destination Table for the network shown in Figure 12 using a trip length distribution based on a Gamma function $(\alpha=2, \beta=2)$.

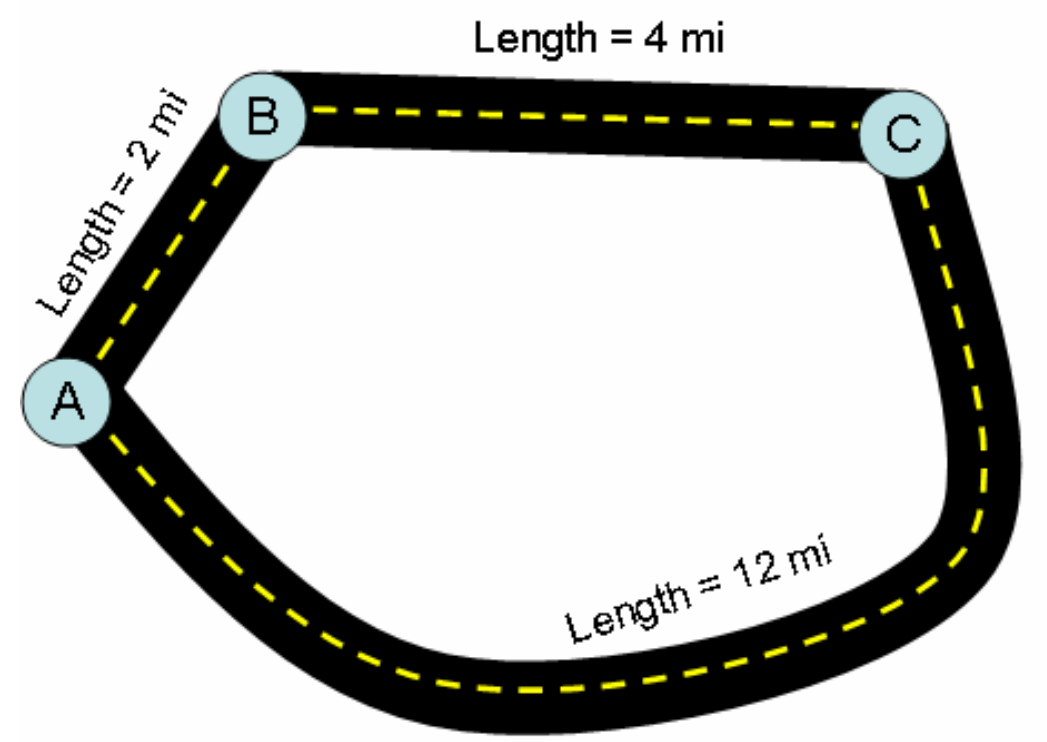

Figure 12: Example Network: Case Study Origin-Destination

Determine the shortest path between each pair of intersections:

Table 7: Shortest Paths for O-D Table Determination Example

$\begin{array}{cc}\text { O-D } & \text { Shortest } \\ \text { Pair } & \begin{array}{c}\text { Path Length } \\ \text { (mi) }\end{array} \\ (A, B) & 2 \\ (A, C) & 6 \\ (B, A) & 2 \\ (B, C) & 4 \\ (C, A) & 6 \\ (C, B) & 4\end{array}$

For each O-D Pair, use the shortest path length (Table 7) to find the value of the Gamma probability density function from Figure 11. A spreadsheet program such as Microsoft Excel can be used to expedite these calculations. Enter these values into the origin destination table (Table 8). 
Table 8: Origin-Destination Table for O-D Table Determination Example

$\begin{array}{cccc} & A & B & C \\ A & - & 0.18 & 0.07 \\ B & 0.18 & - & 0.14 \\ C & 0.07 & 0.14 & -\end{array}$

2.4.4 Calculating the Safe Lengths

Once data was obtained, formatted and matched with the appropriate link from the GIS map, and the origin-destination table was formed, the Bicycle Compatibility Index was calculated for each link in the network using spreadsheets. The BCI was multiplied by the link length to determine the Safe Length of each segment. This data was then imported into TransCAD.

\section{$\underline{\text { Safe Length Sample Calculation }}$}

For Sylvia Street between Grant Street and Vine Street

Data:

$A A D T=179$ vpd in 2003

$85^{\text {th }}$ Percentile Speed $=28 \mathrm{mph}$

Number of Lanes $=2$

Road Width $=33 \mathrm{ft}$

Segment Length $=0.12 \mathrm{mi}$

Parking Occupancy Exceeds 30\%

K-Factor $=0.1$
No Existing Bike Lane

In a Residential Area

Parking Lane Width $=6 \mathrm{ft}$

Annual Growth Factor $=3 \%$

Adjustment Factor $=0.3$ (assumed)

Directional Split $=0.55$

Intermediate Calculations:

Curb Lane Width $=($ Road Width $-2 *$ Parking Lane Width $) /$ Number of Lanes

$$
\begin{aligned}
& =(33 \mathrm{ft}-2 * 8 \mathrm{ft}) / 2 \\
& =10.5 \mathrm{ft}
\end{aligned}
$$

Curb Lane Volume $=A A D T *$ Directional Split $*$ K-Factor $*($ Number of Lanes $/ 2)$

$$
\begin{aligned}
& =179 v \mathrm{vd} * 0.55 * 0.1 *(2 / 2) \\
& =10 \mathrm{vph}
\end{aligned}
$$


Inputs:

$B L \quad=0$

$B L W=0$

$S P D=28 \mathrm{mph}$

$C L W=8.5 \mathrm{ft}$

$C L V=10 \mathrm{vph}$

$O L V=0$

$P K G=1$

$A R E A=1$

$A F \quad=0.3$

\section{Calculations:}

$$
\begin{aligned}
B C I & =3.67-0.966 * B L-0.125 * B L W-0.152 * C L W+0.002 * C L V+0.0004 \\
& * O L V+0.035 * S P D+0.506 * P K G-0.264 * A R E A+A F \\
& =3.67-0.966 * 0-0.125 * 0-0.152 * 8.5+0.002 * 10+0.0004 \\
& * 0+0.035 * 28+0.506 * 1-0.264 * 1+0.3 \\
& =3.920
\end{aligned}
$$

Safe Length $\quad=B C I *$ Segment Length

$$
\begin{aligned}
& =3.920 * 0.12 \mathrm{mi} \\
& =0.470 \text { Safe Miles }
\end{aligned}
$$

Definitions for variables used to calculate BCI can be found in Table 4.

\subsubsection{Traffic Assignment and Outputs}

TransCAD's traffic assignment function was used to load the links. Bicycle flow was assigned using the all or nothing method, due to the low likelihood of bicycle congestion. The flow on each link was multiplied by its Safe Length, and then these values were summed to create the Total Network Path Safe Length for the existing network. The bicycle flow map for the existing facilities (Figure 13) shows that links that maintain a high level of service are the most used links in the network. Figure 13 and all subsequent flow maps also show the Level of Service of each link in the network for bicyclists based on the BCI. Bicycle volumes are highest on roadways with bike lanes. The location of the existing bicycle lanes can be seen in Figure 14. Roadways that provide access to several areas of relatively high road densities also carry high flows. The Total Network Path 
Safe Length of the existing network is 210,619 Safe Miles, or 3,588 Safe Miles per mile of roadway in the network, and the average trip length is 1.78 miles. These values will serve as a basis for comparison of the six scenarios. Once the tool was used to determine the existing network properties, it was possible to determine the impacts of bicycle improvements, as well as providing insight into potential locations for these improvements. 


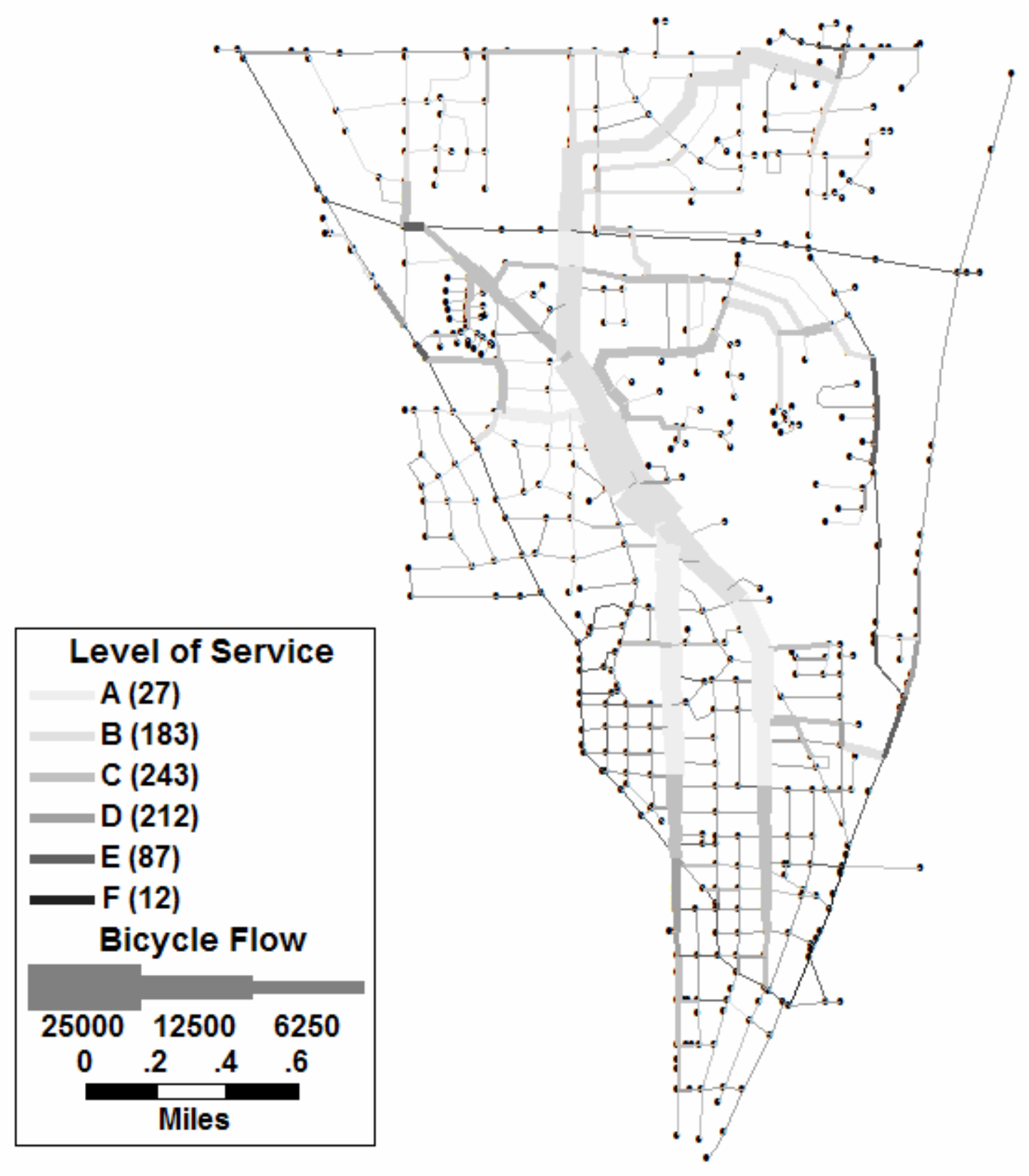

Figure 13: Bicycle Flow Map for the Existing Facilities in West Lafayette 


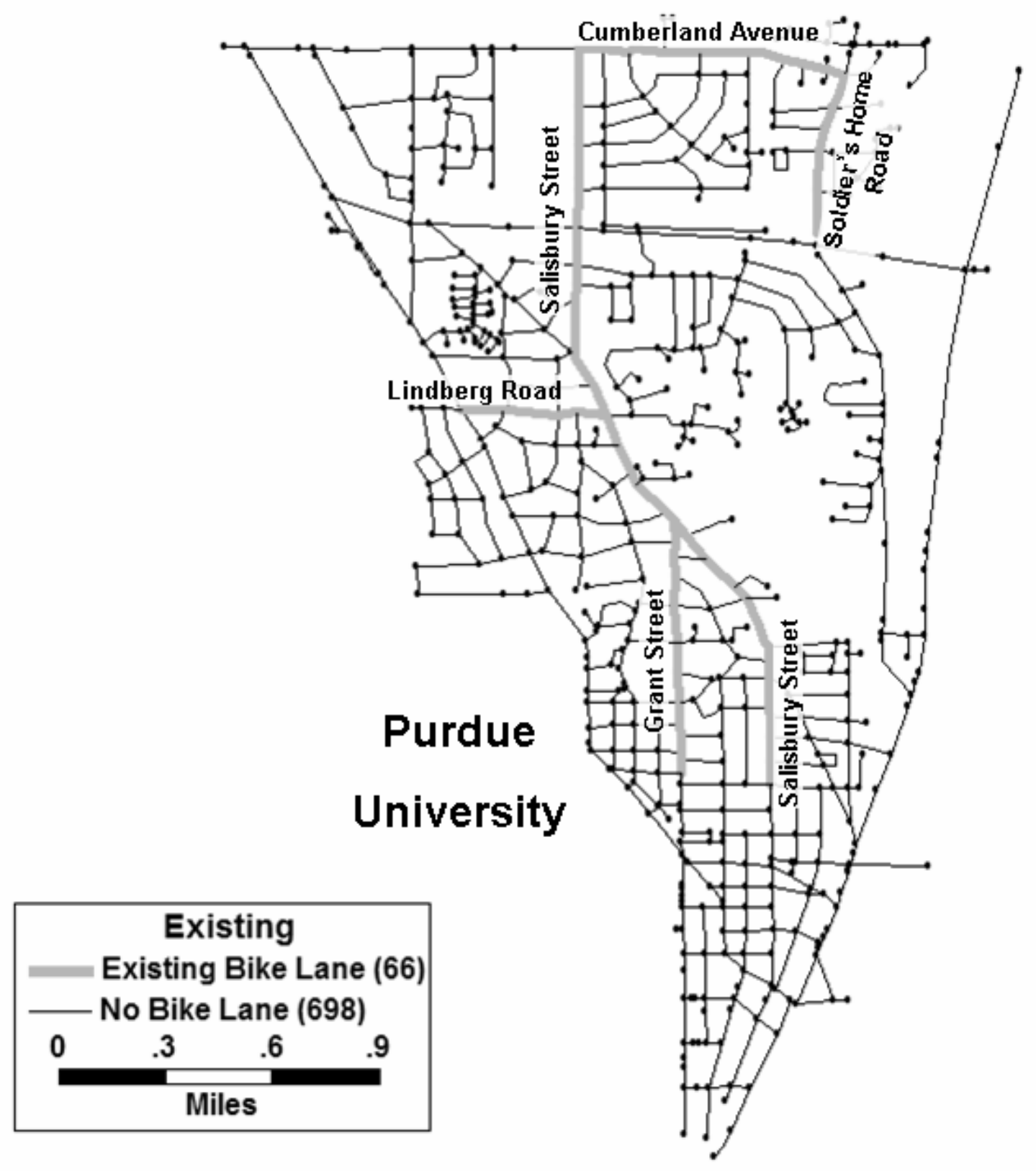

Figure 14: Existing Bike Lanes in West Lafayette

\subsubsection{Northwestern Scenario}

As seen in Figure 13, much of the bicycle flow in the existing network was directed towards the center of the study area, avoiding the more dangerous links on the edges of 
the graph. In this scenario, a bike lane is added to Northwestern Avenue (US 231) along the western edge of the network, and continues on Yeager Road until it meets Cumberland Avenue. A map of these facilities can be seen in Figure 15. Northwestern Avenue was chosen as a potential location for improvement due to its proximity to the campus of Purdue University, as well as the high speeds and volumes experienced on the roadway. Figure 16 shows that the flow pattern was not much different from the existing pattern. Northwestern attracted a low number of trips away from the existing bike lanes, and only experiences high flow rates on isolated segments. An existing bike lane in the Northwest region of the network became more accessible, leading to an increase in assigned trips. The Total Network Path Safe Length for this scenario was 206,094 Safe miles, which is a decrease of $2.15 \%$ from the existing network, with an increase in average bicycle trip length of $0.36 \%$. The small benefit gained in this scenario provided evidence that improvements along the edge of the study area are not likely to be assigned a large amount of flow due to a reduced number of adjacent links. In order to provide realistic results when using an artificial origin-destination table, the study area should center on the most populated neighborhoods. The trip length distribution method underestimates the flows on links on the outer edge of the study area, because of the lack of adjacent destinations. 


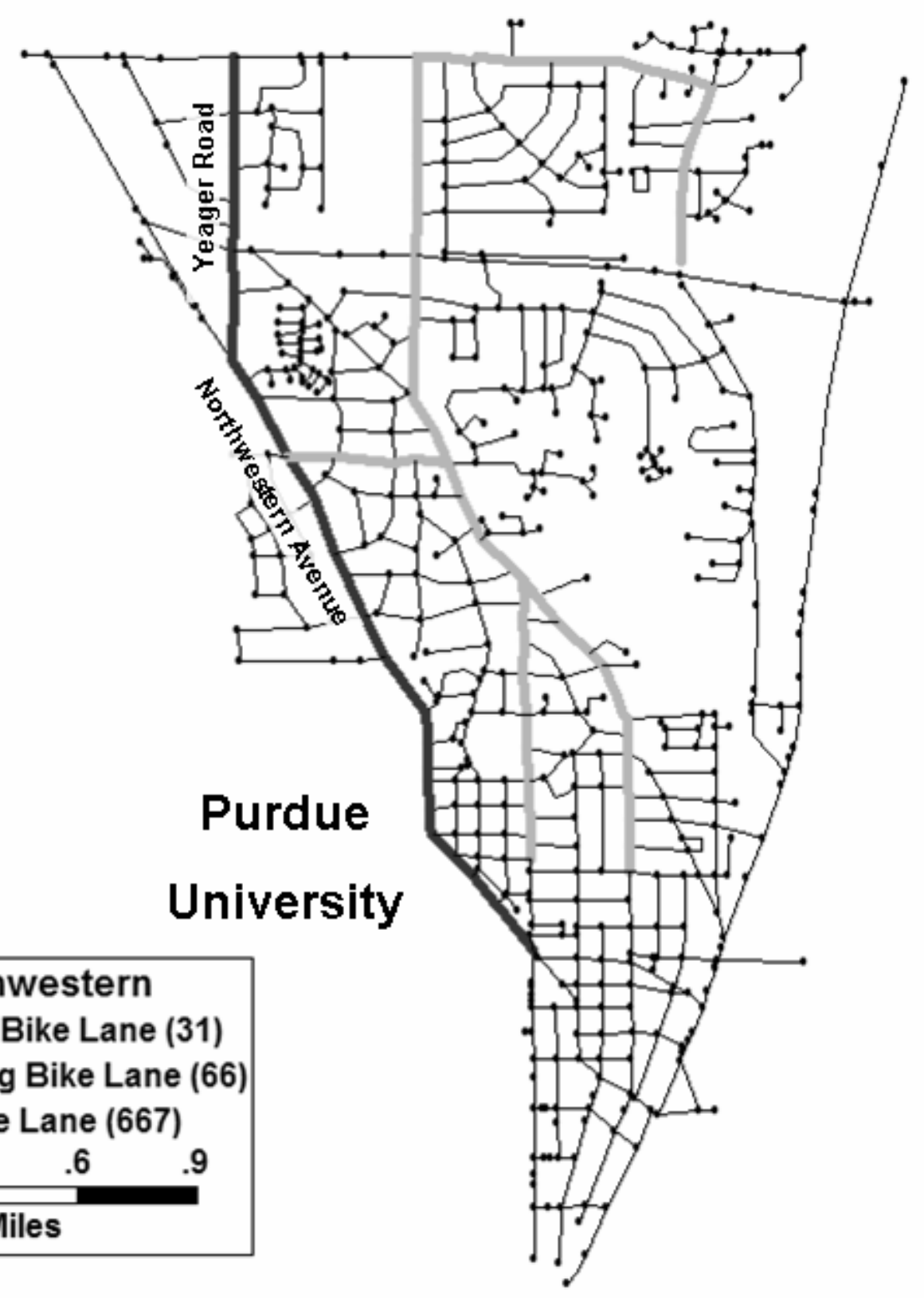

Figure 15: Northwestern Case Bike Lanes 


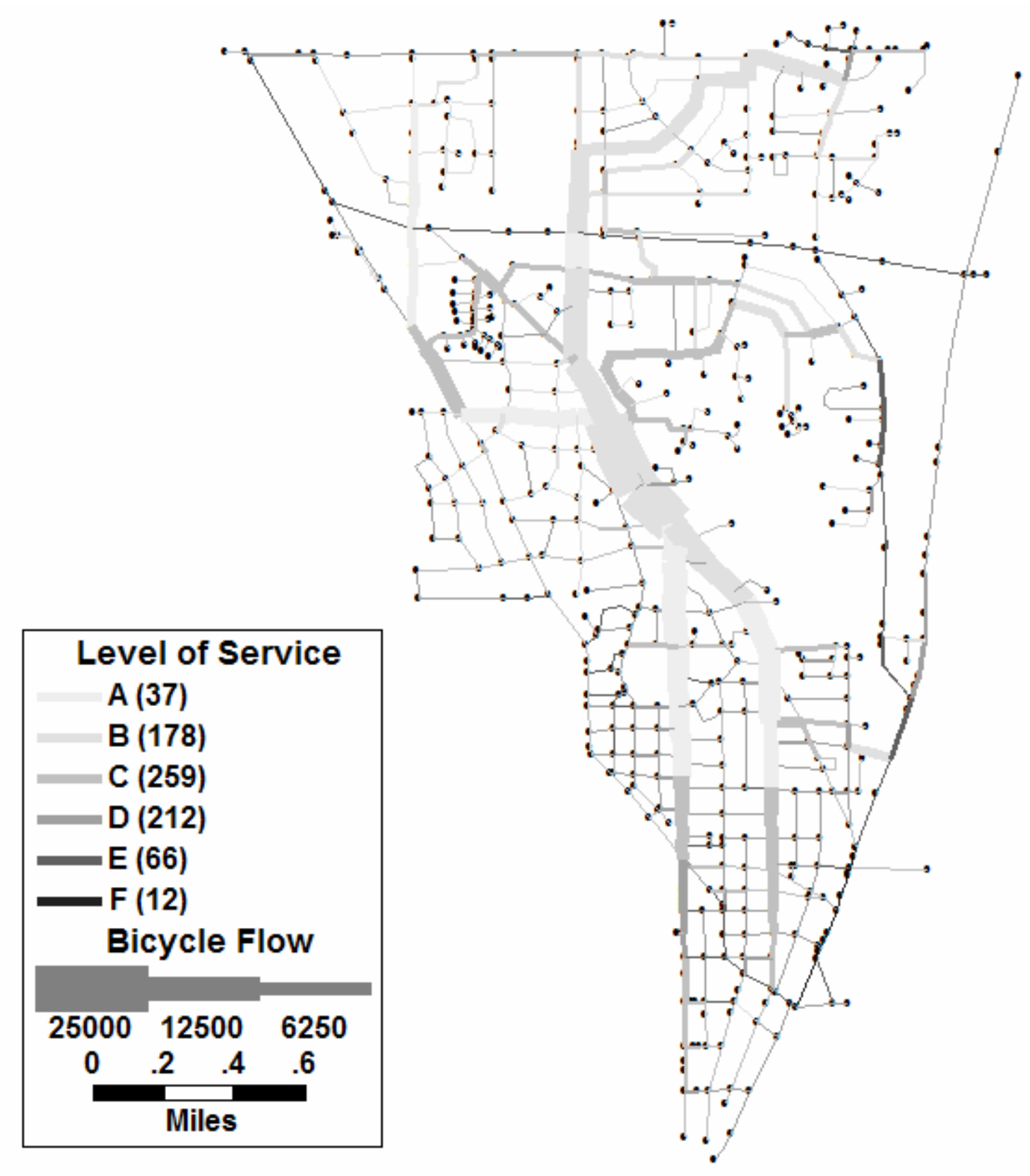

Figure 16: Bicycle Flow Map for Northwestern Scenario

\subsubsection{Ravina-Garfield Scenario}

After the Northwestern scenario, it was desirable to place improvements along a corridor that was not on the edge of the map, and was in a dense residential area. A bike lane was 
added along the corridor that contains Ravina Road and Garfield Road. The location of this facility can be seen in Figure 17. This improvement had little significant impact on the flow pattern, seen in Figure 18. The lack of effect of the new bike lane can likely be attributed to its proximity to the existing facilities. The trips likely to use the new facilities were not diverted from the paths they used in the existing network. This resulted in a Total Network Path Safe Length of 210,257 , which was a very small $(0.17 \%)$ reduction from the existing network. The average bicycle trip length decreased by $0.06 \%$, which is not significant. This scenario makes it clear that bicycle facilities should not be placed near an existing facility traveling in the same direction. Placing a new facility that will serve a similar area to an old facility is likely not an efficient use of resources, because those who would benefit from the new facility already have a viable alternative. 


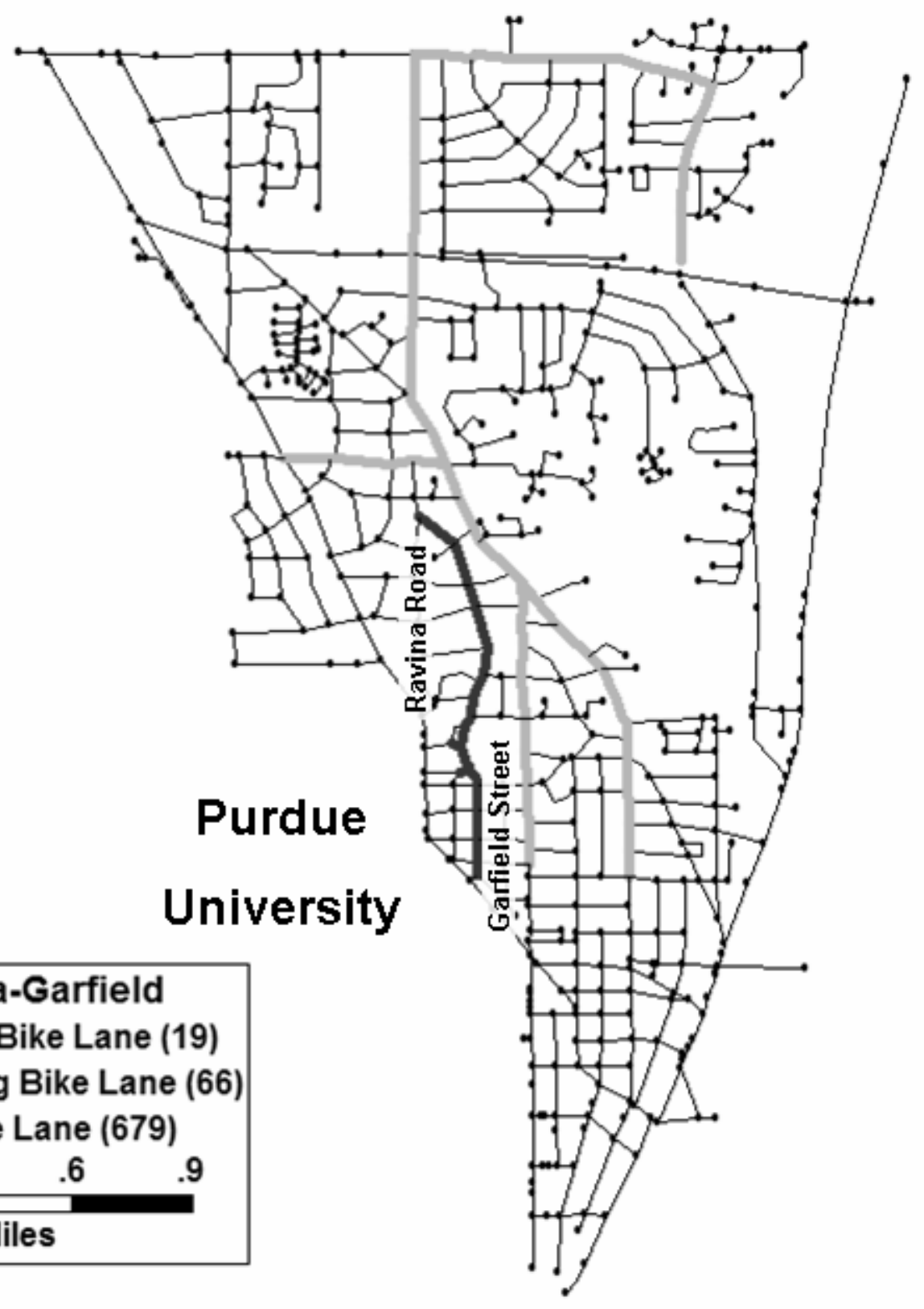

Figure 17: Ravina-Garfield Case Bike Lanes 


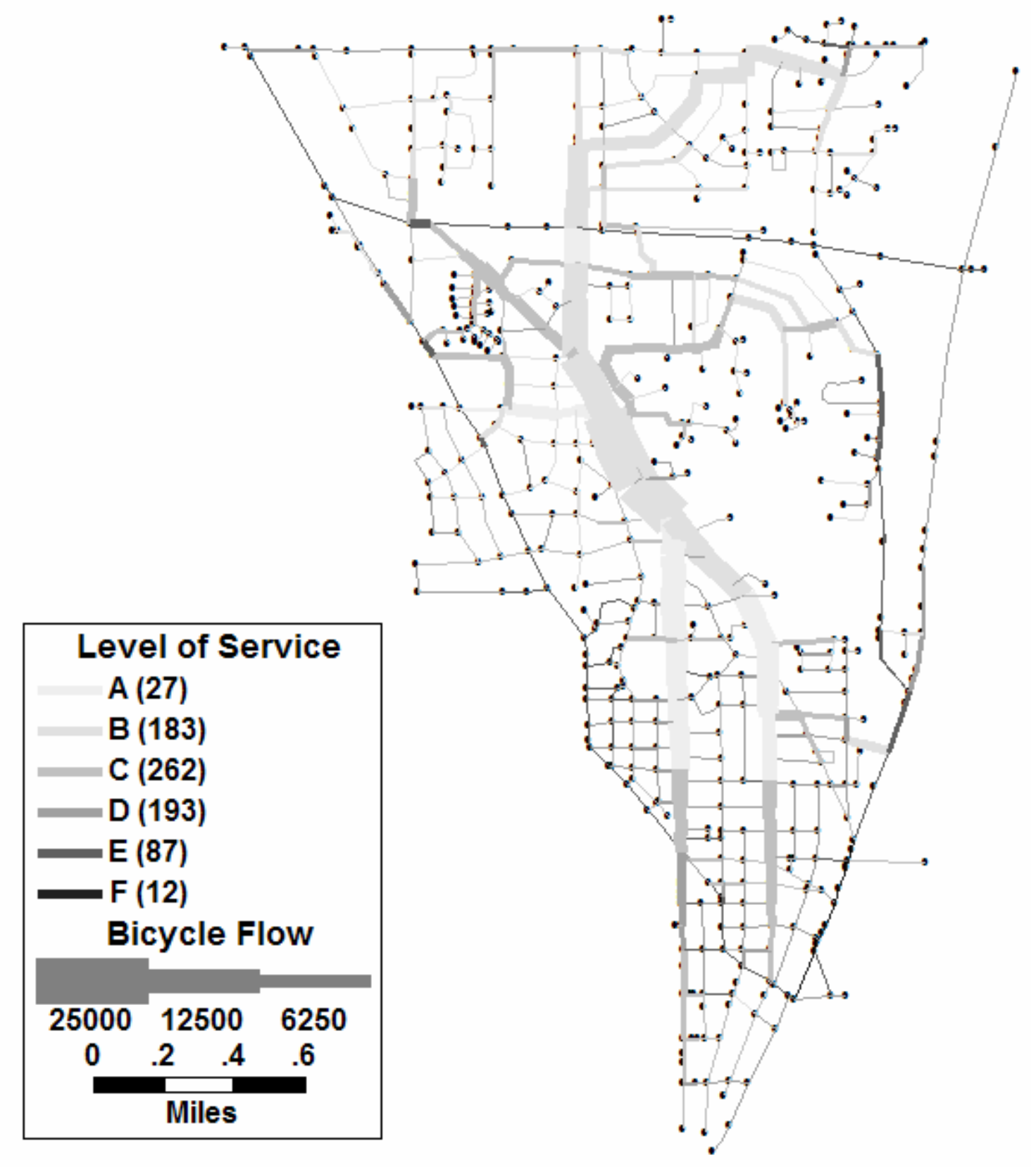

Figure 18: Bike Flow Map for Ravina-Garfield Scenario 


\subsubsection{Arbitrary Placement Scenario}

This scenario attempts to simulate placement of bicycle facilities without regard to the connectivity of the network by adding bicycle lanes to various segments without considering the network properties. The location of these lanes is shown in Figure 19. Some of these lanes are placed near existing facilities, and some are isolated from the other bike lanes. The flow pattern for this scenario, available as Figure 20, is somewhat different from the existing map. Many trips are diverted from the existing facilities to proximate links with added bike lanes. This scenario resulted in a Total Network Path Safe Length of 200,548 Safe miles, a $4.78 \%$ decrease from the existing network. This scenario was surprisingly successful. The large decrease can be attributed to the extremely low BCI values due to the bike lanes Hillcrest Road and Woodland Avenue, at 0.95 and 0.57 respectively. These roads maintain very low Safe Length values, and attract a large number of trips, reducing the Total Network Path Safe Length. This scenario experienced a $9.82 \%$ increase in the average bicycle trip length, indicating that it improved the attractiveness of several paths that take more circuitous routes from origin to destination. 


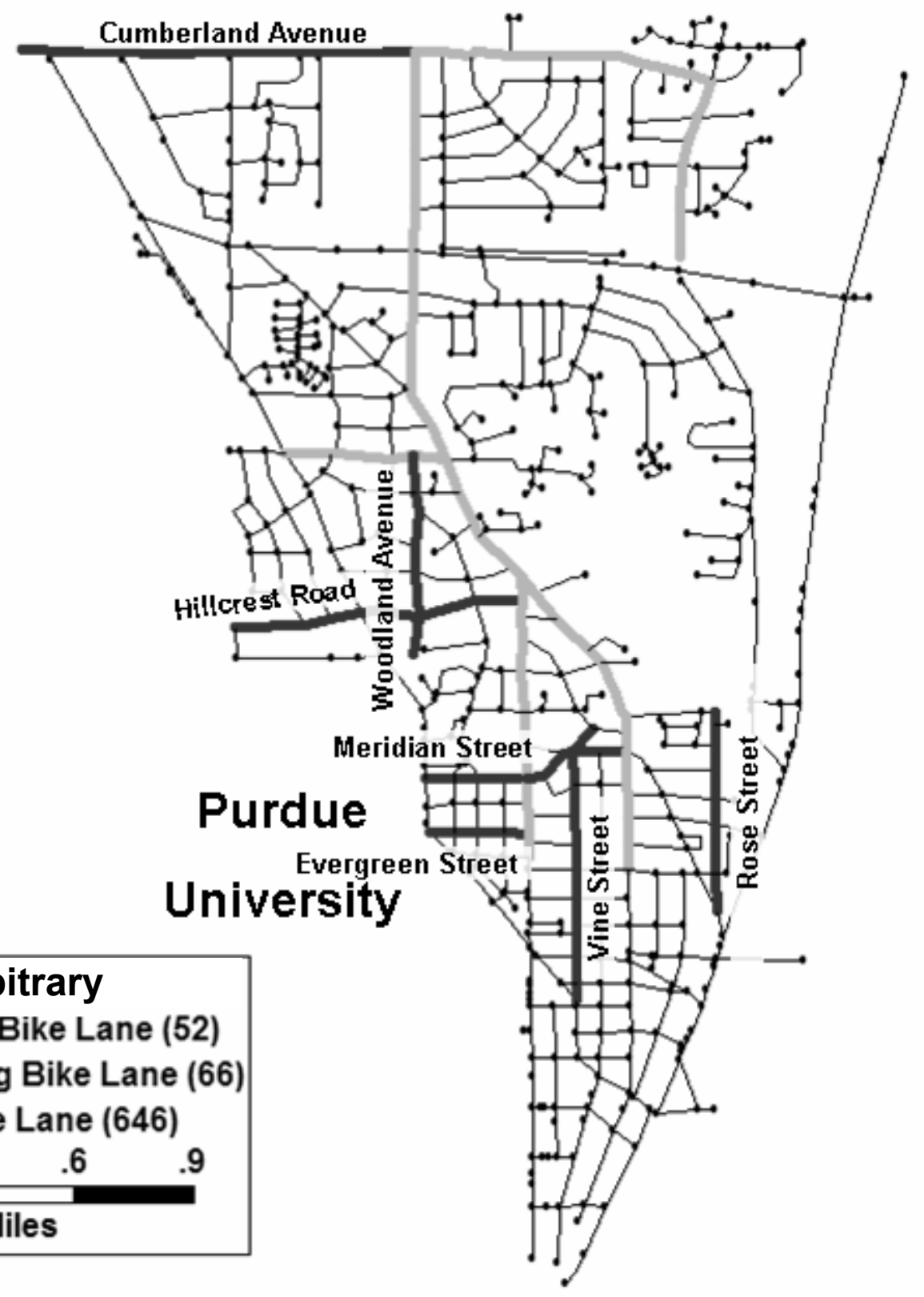

Figure 19: Arbitrary Placement Case Bike Lanes 


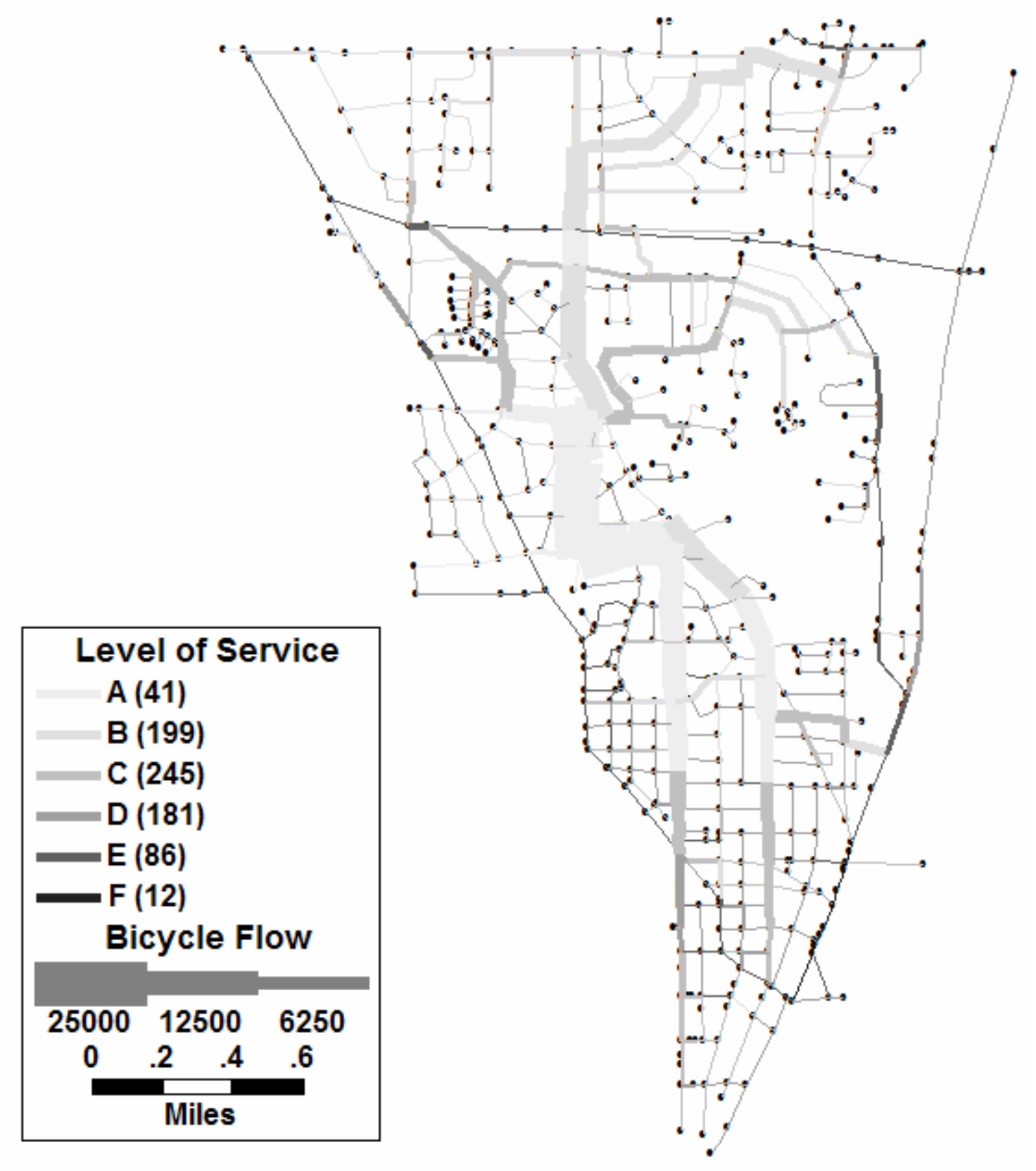

Figure 20: Bike Flow Map for Arbitrary Placement Scenario 


\subsubsection{Bike Paradise Scenario}

The construction of a bike lane on every road in a network is improbable. For the purposes of this case study, however, that scenario can aid in the determination of the optimal location for bicycle improvements. By placing a facility on each roadway, the tool will uncover routes with a large amount of potential demand, allowing for the identification of links that would be heavily traveled if a bike lane were present. Figure 21 shows the location of the bike facilities, which cover the entire network. In Figure 22, it is obvious that a few links much more heavily traveled than others. While some of these links would probably not be improved due to their proximity to existing facilities, many of the high flow links are not redundant, and the construction of a bike lane on these links could drastically improve the quality of the network. The Total Network Path Safe Length of this scenario is $42.62 \%$ lower than the existing network at 120,851 Safe miles. The average bicycle trip length was decreased by $6.41 \%$. These vast improvements are to be expected with the decrease of the $\mathrm{BCI}$ on most links in the network, The great reduction in $\mathrm{BCI}$ causes the length of the roadway to have greater influence in the bicycle route choice model. 


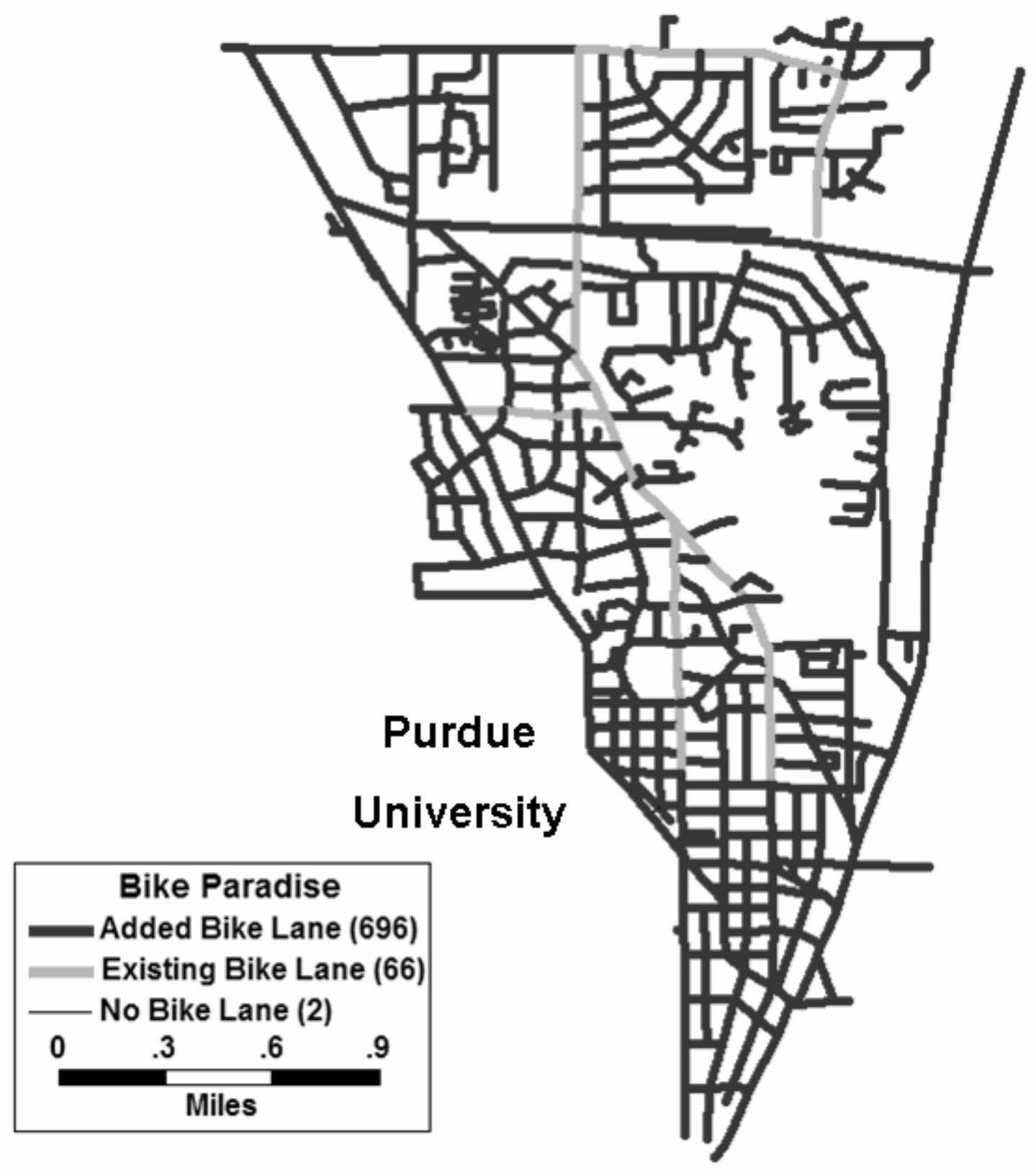

Figure 21: Bike Paradise Case Bike Lanes 


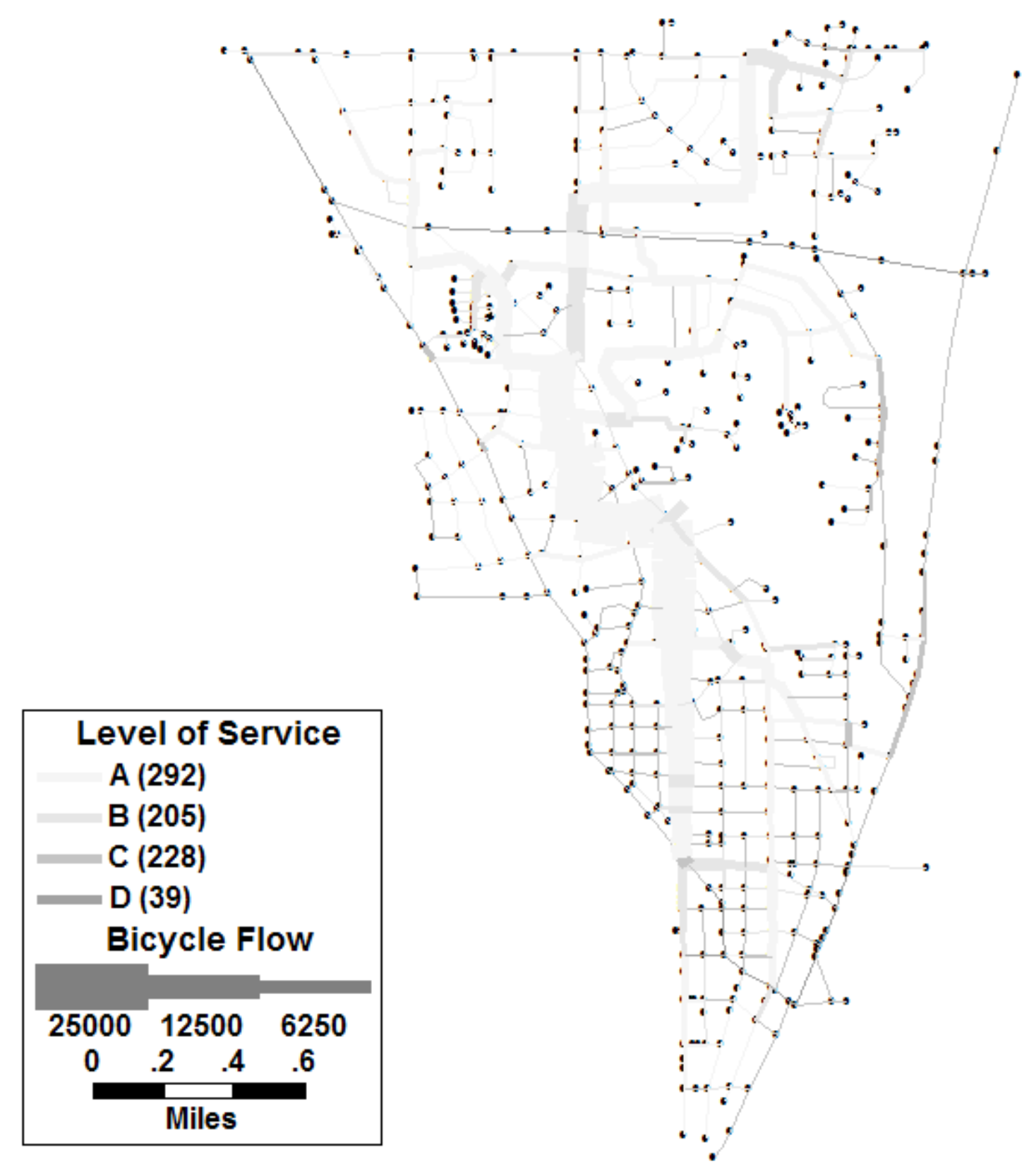

Figure 22: Bike Flow Map for Bike Paradise Scenario 


\subsubsection{High Volume}

In the Bike Paradise scenario, potentially valuable links were identified by placing a bike lane on each link, and determining which links currently lacking bicycle facilities were assigned the most trips. Kent Avenue, Indian Trail Drive, Sycamore Lane, Fowler Avenue, Carlisle Road, and Henderson Street were found to be the most qualified roadways. In this scenario, a bike lane was added on each of these high bicycle volume facilities, as well as on a limited number of other links to connect these facilities to existing bike lanes. The location of these bike lanes can be seen in Figure 23. From Figure 24 it can be seen that the flow is different than depicted on the existing flow map (Figure 13) on most of the segments with new facilities. The new facilities each carry a significant amount of flow, validating their location. The Total Network Path Safe Length of this scenario is 180,052 Safe miles, which, excluding the Bike Paradise scenario, is the largest reduction from the existing network achieved in this study, at $14.51 \%$. The average bicycle trip length increased $5.16 \%$, as trips were attracted from more direct routes to the new bike lanes. 


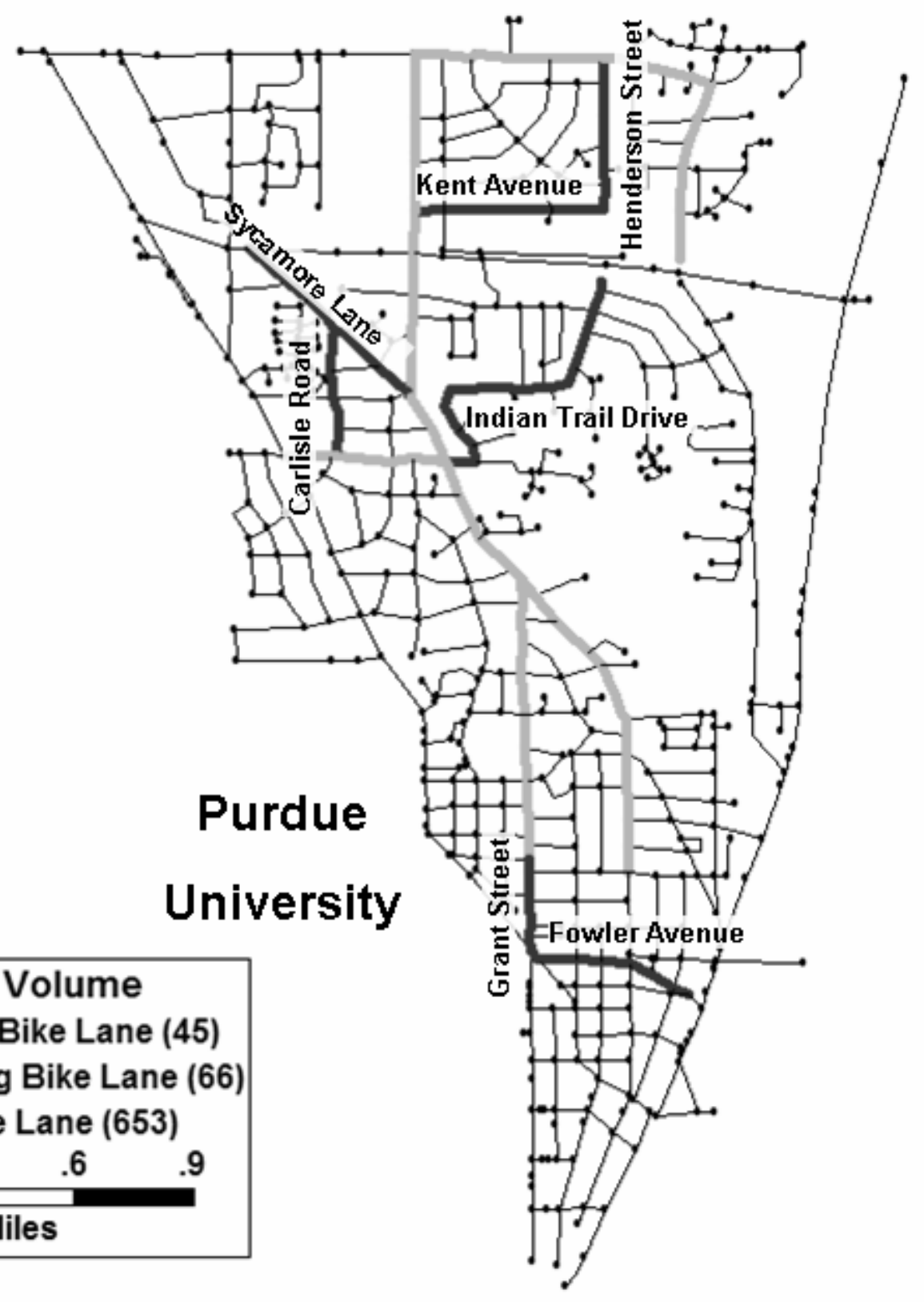

Figure 23: High Volume Case Bike Lanes 


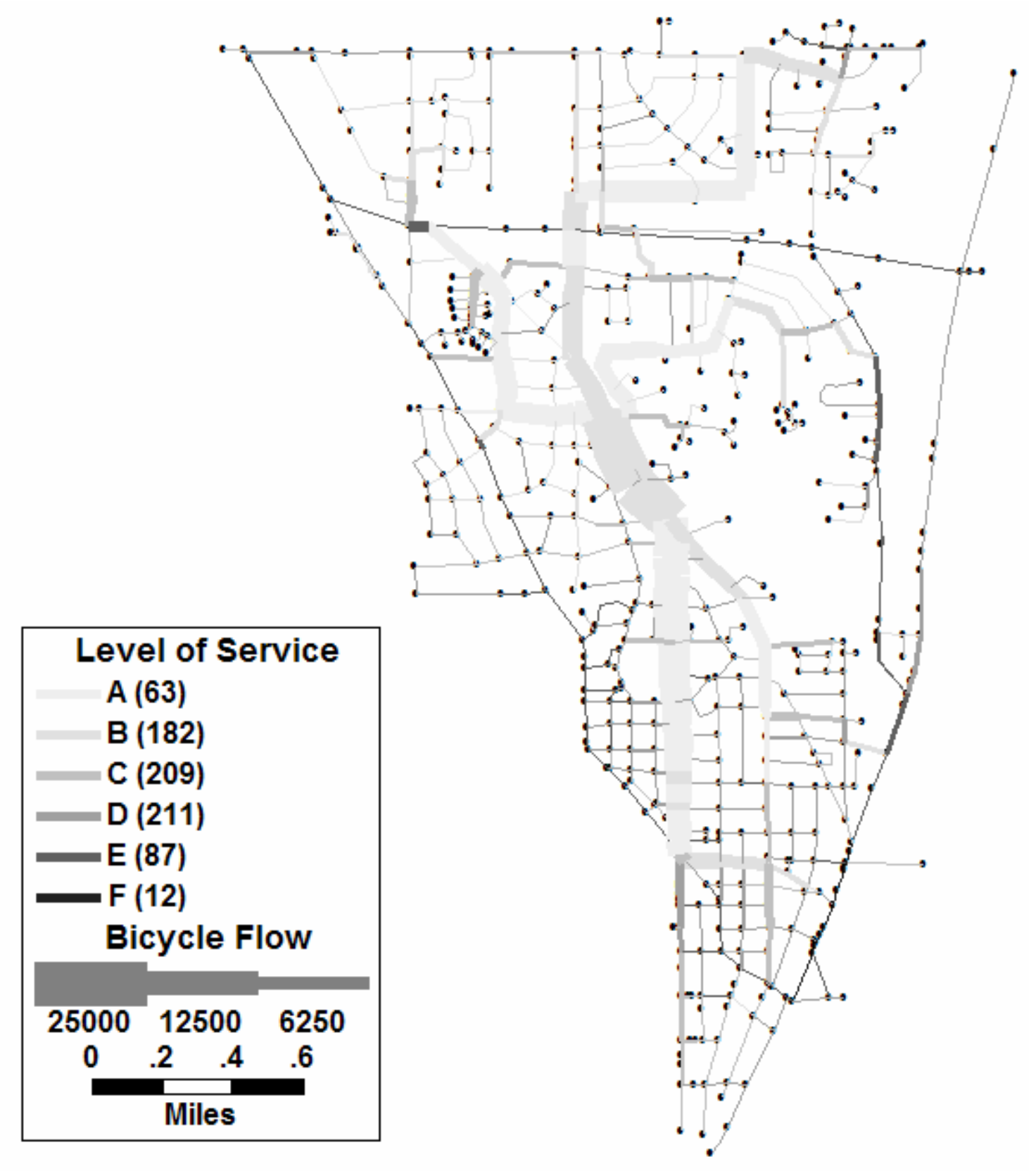

Figure 24: Bike Flow Map for High Volume Scenario 


\subsubsection{Worst Links Scenario}

The final scenario tested placed bicycle facilities on sections of roadway with the worst Bicycle Compatibility Index. This method is meant to improve the links perceived to be most dangerous by riders. These unsafe roadways, River Road, Northridge Road, Stadium Avenue, Allen Street, Quincy Street, and Rose Street each were given bike lanes, as seen in Figure 25. The worst BCI along these roads can be seen in Table 9. These lanes are disconnected in many instances, and are concentrated in the areas of high roadway density in West Lafayette, due to the higher traffic volumes. Improving the links with high BCI values did not significantly alter the flow pattern, as seen in Figure 26 . The Total Network Path Safe Length decreased $1.17 \%$ to 208,159 Safe miles. The average trip length was reduced by $0.29 \%$ in this scenario. The new bike lanes do not attract a large amount of trips, because other links maintain a higher level of safety than the improved links. Improving the worst links does not appear to improve the quality of the network, as they are generally avoidable.

Table 9: BCI of Roads Selected for Improvement in Worst Links Scenario

$\begin{array}{ccc}\text { Street } & \text { BCI } & \text { LOS } \\ \text { Allen Street } & 4.515 & \text { E } \\ \text { Northridge Drive } & 4.515 & \text { E } \\ \text { Quincy Street } & 4.483 & \text { E } \\ \text { Rose Street } & 4.087 & \text { D } \\ \text { River Road } & 5.662 & \text { F } \\ \text { Stadium Avenue } & 4.446 & \text { E }\end{array}$




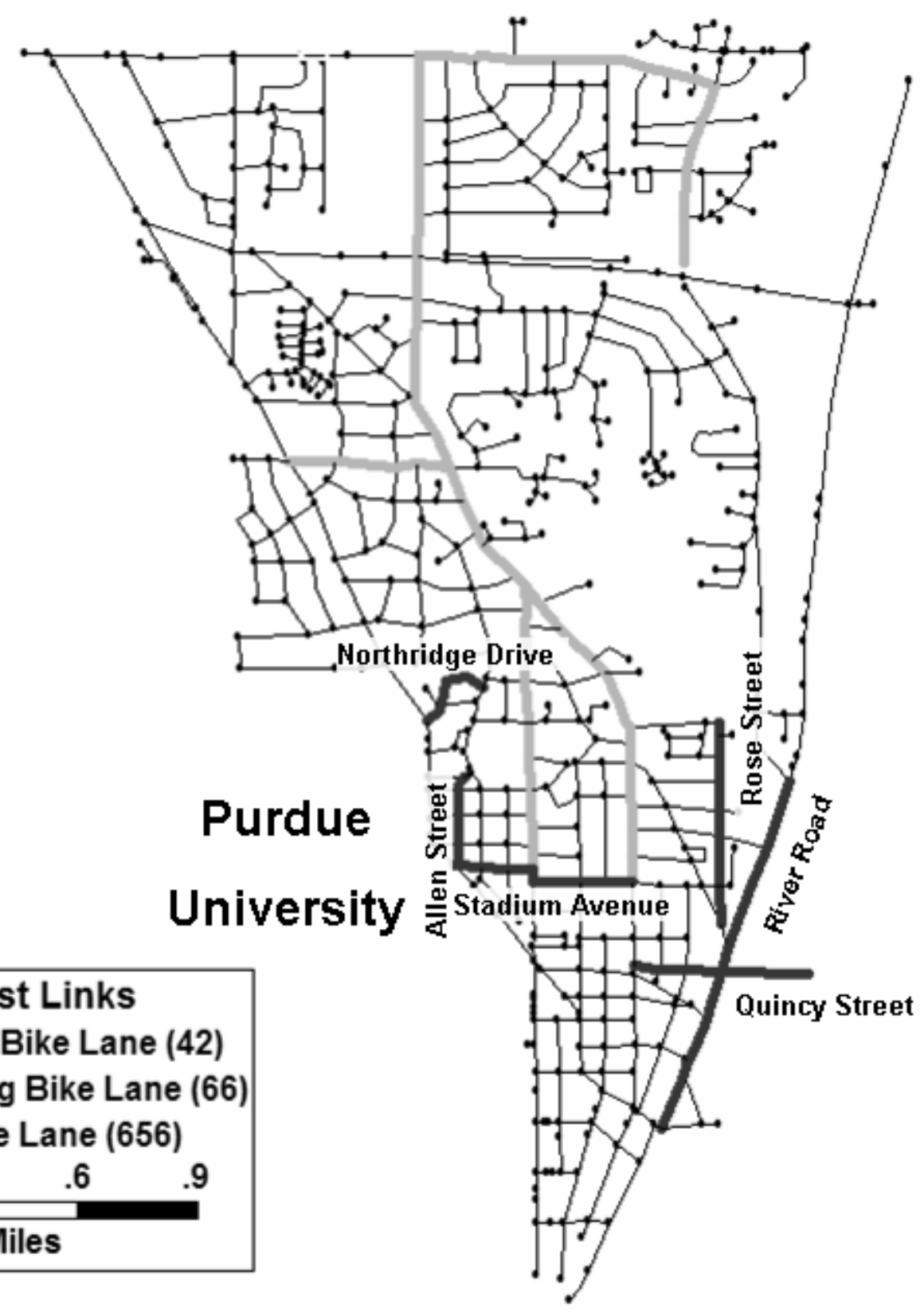

Figure 25: Worst Links Case Bike Lanes 


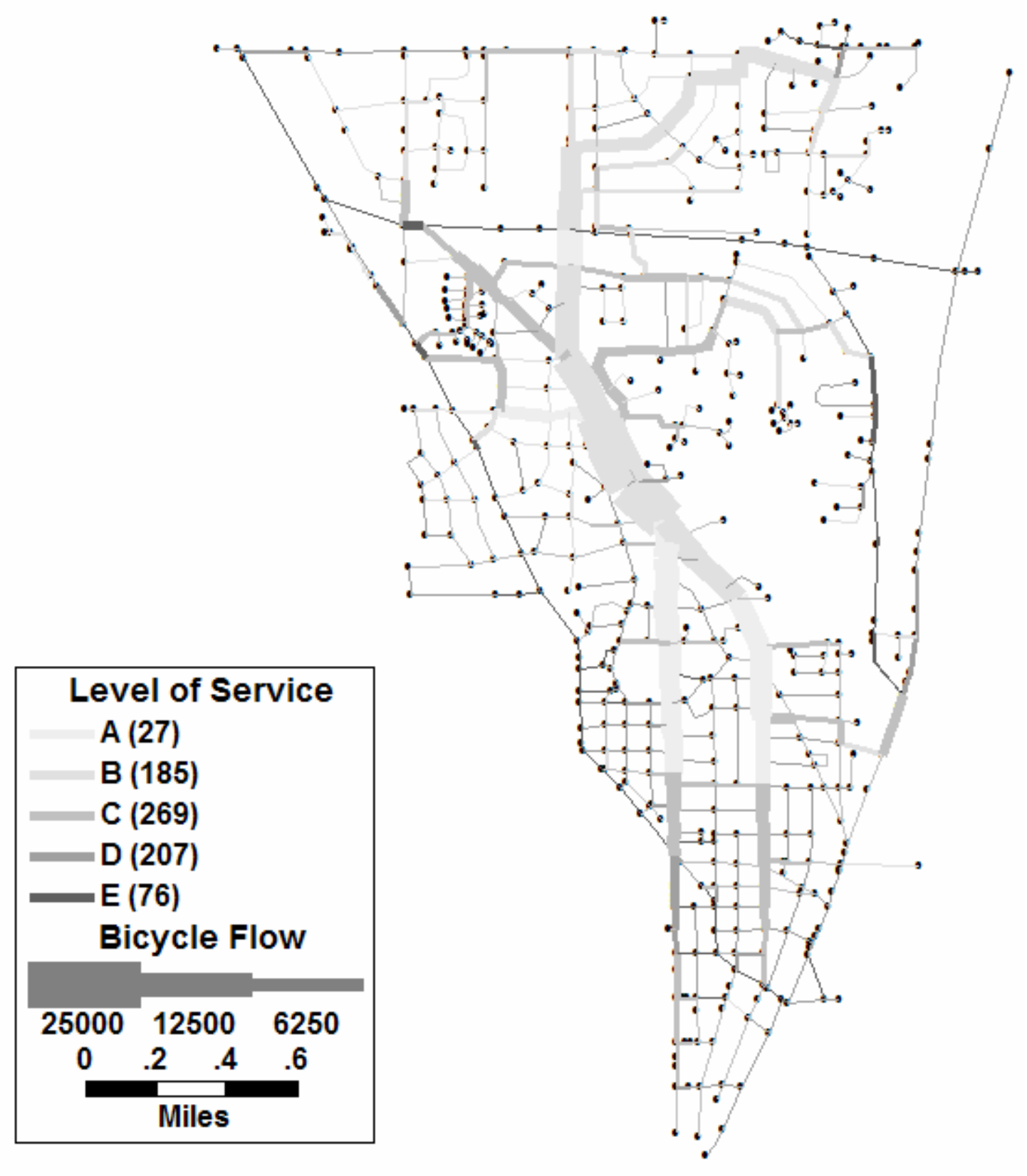

Figure 26: Bike Flow Map for Worst Links Scenario 


\subsubsection{Addition of Specific Trip Generators}

Purdue University attracts a large amount of bicycle trips from the surrounding area. To test the ability of the BNAT to account for a prominent trip generator, two sets of bicycle trips were added to the origin-destination matrix. The first set contained trips between three locations on the Purdue campus and nearby apartment complexes, including some apartments not located within the network. These locations can be seen in Figure 27. The second set distributes 5,000 trips from the three Purdue campus locations to each intersection in the network using the trip length distribution (Figure 11). The flow map with the added Purdue Trips (Figure 27) shows little change from the existing flow pattern (Figure 13). The added trips increased volumes on the roads that already experienced high bicycle volumes, avoiding the links with high BCI values. This method was successful in showing that the BNAT can be used with any trip table. 


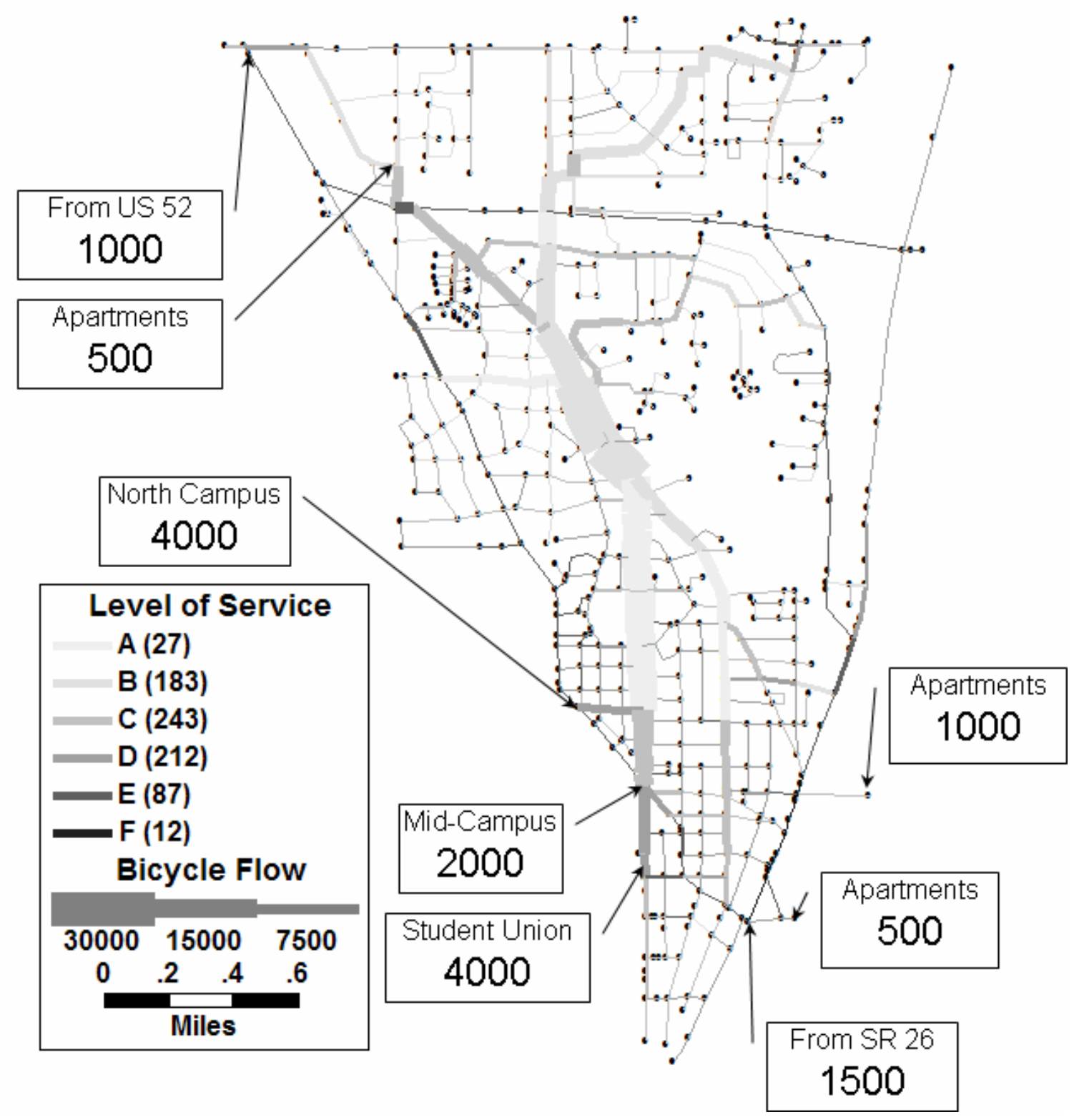

Figure 27: Bike Flow Map with Specific Trip Generator Locations 


\subsubsection{Case Study Results}

This case study provided interesting results, which are summarized in Table 10. As expected, the High Volume scenario caused the greatest reduction in Total Network Path Safe Length, excluding the Bike Paradise scenario. The use of the ideal bicycle network to determine which facilities bicyclists would prefer to use when most links are safe allowed for a simple determination of the most efficient use of bicycle resources. Scenarios that attempted to attract users from their existing routes by improving low volume facilities with high existing Safe Lengths were much less successful. The Northwestern, Ravina-Garfield, Arbitrary Placement, and Worst Links scenarios produced smaller reductions in the Total Network Path Safe Length. The improvement in the Total Network Path Safe Length indicates an improvement in the quality of the bicycle network and in its safety. By looking at the change in Total Network Path Safe Length with respect to the length of added bike lanes, an approximate estimation of the improvement relative to cost can be obtained (Table 10), assuming the construction cost of the bike lane is constant per unit length. This benefit/cost measure shows the inefficiency of the Bike Paradise scenario, as the drastic improvement in Total Network Path Safe Length is not as high relative to the large length of added bike lanes. It is clear from this measure that the High Volume scenario is the most efficient, in addition to being the most effective. 
Table 10: Case Study Results

\begin{tabular}{|r|c|c|c|c|c|c|c|}
\hline & Existing & Arbitrary & $\begin{array}{c}\text { North- } \\
\text { western }\end{array}$ & $\begin{array}{c}\text { High } \\
\text { Volume }\end{array}$ & $\begin{array}{c}\text { Ravina - } \\
\text { Garfield }\end{array}$ & $\begin{array}{c}\text { Worst } \\
\text { Links }\end{array}$ & $\begin{array}{c}\text { Bike } \\
\text { Paradise }\end{array}$ \\
\hline TNL (mi) & 58.7 & 58.7 & 58.7 & 58.7 & 58.7 & 58.7 & 58.7 \\
\hline TNPSL (smi) & 210619.2 & 200548.3 & 206094.5 & 180052.9 & 210257.9 & 208159.0 & 120851.8 \\
\hline TNPTL (mi) & 91950.6 & 100982.7 & 92284.7 & 96694.4 & 91892.2 & 91685.7 & 86055.4 \\
\hline INT & 576 & 576 & 576 & 576 & 576 & 576 & 576 \\
\hline TNPSL/TNL & 3588.0 & 3416.5 & 3511.0 & 3067.3 & 3581.9 & 3546.1 & 2058.8 \\
\hline TNPSL/INT & 365.7 & 348.2 & 357.8 & 312.6 & 365.0 & 361.4 & 209.8 \\
\hline ABLL (mi) & - & 2.79 & 2.48 & 3.19 & 1.26 & 2.82 & 43.32 \\
\hline$\Delta$ TNPSL (smi) & - & $-4.78 \%$ & $-2.15 \%$ & $-14.51 \%$ & $-0.17 \%$ & $-1.17 \%$ & $-42.62 \%$ \\
\hline \multirow{2}{*}{$\Delta$ TNPSL/ABLL } & - & -3609.6 & -1824.5 & -9581.9 & -286.7 & -872.4 & -2072.2 \\
\cline { 2 - 7 } & & $-1.71 \%$ & $-0.87 \%$ & $-4.55 \%$ & $-0.14 \%$ & $-0.41 \%$ & $-0.98 \%$ \\
\hline$\Delta$ TNTL/ABLL & - & $1.7 \%$ & $0.9 \%$ & $4.5 \%$ & $0.1 \%$ & $0.4 \%$ & $1.0 \%$ \\
\hline TT & 51518.3 & 51518.3 & 51518.3 & 51518.3 & 51518.3 & 51518.3 & 51518.3 \\
\hline ATL (mi) & 1.78 & 1.96 & 1.79 & 1.88 & 1.78 & 1.78 & 1.67 \\
\hline$\Delta$ ATL (mi) & & $9.82 \%$ & $0.36 \%$ & $5.16 \%$ & $-0.06 \%$ & $-0.29 \%$ & $-6.41 \%$ \\
\hline TNL: Tota N & & & &
\end{tabular}

TNL: Total Network Length - The length of the road network in miles.

TNPSL: Total Network Path Safe Length - The sum of all Safe Length shortest paths between each pair of intersections weighted by the bicycle trips between them.

TNTL: Total Network Path Travel Length - The sum of the length in miles traveled by users between each pair of intersections following Safe Length shortest paths weighted by the bicycle trips between them.

INT: Number of intersections in the network. This includes some driveways and other access points.

smi: Safe miles - Distance weighted by BCI; the product of the BCI and length.

ABLL: Added Bike Land Length - Linear miles of bike lane added to the network in a given scenario.

TT: Total Trips - The sum of all trips assigned by the trip length distribution, for example: the sum of the entries in Table 8 (TT for the Origin-Destination Table Determination Example $=0.77$ )

ATL: Average Travel Length - The distance, in miles, of the average bicycle trip on the network.

LOS: Level of Service - All level of service designations in this report are based on the Bicycle Compatibility Index 


\subsection{Conclusions and Future Research}

The Bicycle Network Analysis Tool provides a method that can be used to aid in the decision-making processes related to public investment. This tool also offers insight into areas of research to aid in the future of bicycle transportation. The development of a bicycle route choice model would increase the usefulness of this tool by increasing its accuracy. While the model presented here is a simple and logical one, it likely can be improved. A well-designed survey is needed to verify or refine the hypothesis that a product of distance and BCI is the basis for a bicyclist's route choice. Good data on the origin-destination patterns of bicycle trips in a study area would greatly improve the quality of the BNAT's results. Without such information, this study used a hypothetical bicycle trip length distribution that did not reflect the unique concentration of trip ends that each study area has. A guide to collecting such data would be quite useful to the refinement and application of the BNAT. An analysis of the relationship between the Bicycle Compatibility Index, the Bicycle Level of Service, and bicycle crash data would provide evidence of the validity of the two measures' ability to model network safety in addition to the perceived safety of the bicyclists. Are incidents involving bicyclists more likely to occur on roadways with poor BCI or BLOS values? Are bicyclists more likely to ride on sidewalks along roadways with poor BCI or BLOS values? The bicyclist is the most vulnerable (potential) user of the public roads. Ways to encourage the safe use of roadways by bicyclists is an increasingly important issue for transportation engineers and public officials. 


\section{Chapter 3 - Summary of Project Findings}

Because of the interest in this study, an expanded version of the Technical Summary is presented in this chapter. The two principal goals of the proposed research were:

A. Establish a clear set of criteria by which to evaluate the design of a roadway with respect to potential use by bicyclists. A reasonable set of criteria to evaluate the bicycle components of a roadway design will assist in making those components a routine part of the design process.

B. Determine the most effective way to incorporate bicycle features in transportation planning practice. A procedure that can be used by INDOT, MPOs, and local public agencies to assess the effectiveness of bicycle features in an alternatives analysis would make bicycle planning an integral part of transportation planning.

To address Goal A, the research team examined bicycle crash data and studied previous studies of factors that contribute to real and perceived bicycle safety on roadway links. Regarding Goal B, the link-based measures were incorporated into a network-level system of evaluating proposed improvements and additions to bicycle facilities in an area. In addition, the project's study advisory committee formulated some strategies that INDOT and other jurisdictions could use to enhance bicycle safety. These research activities and findings are summarized in the sections below, culminating in a list of recommended actions to be taken by INDOT and other agencies. 


\subsection{Crash Data}

This study used a database containing summary information on 2,947 crashes involving bicyclists that occurred in Indiana during the years 2003-2005 to investigate possible common factors in these crashes. According to the database, 1,656 of the 2,947 bicyclerelated crashes occurred at an intersection. Over half of all bicycle-related collisions were right angle crashes. "Daylight" was most common condition listed in the database. Under "primary factors" and "contributing factors", "pedestrian action" was most often listed, but this category includes both pedestrians and pedalcyclists.

Because the statewide summary database did not permit a detailed analysis, individual crash reports for the 31 bicycle fatalities that occurred in Indiana during the years 2003-2005, and individual crash reports for the 29 bicycle injuries that occurred in Tippecanoe County during those years were examined in detail. The researchers were looking for design-related factors that might provide the basis for proposing changes to the Indiana Design Manual. The crash report analyses indicated that most bicycle crashes were because of driver or cyclist error. Except for added lighting in some locations, there was no consistent design element that INDOT could improve, except to incorporate bicycle facilities into roadway design wherever possible. A common situation leading to bicycle-motor vehicle collisions was a bicyclist on a sidewalk crossing a driveway. INDOT cannot prevent bicyclists on sidewalks, except to the extent that bicycle lanes that are provided on the adjacent street are viewed by bicyclists as an acceptable place to ride. 
3.2 Factors related to bicycle safety.

In 1997, Sprinkle Consulting Engineers, Inc. developed the Bicycle Level of Service (BLOS). Bicyclists rode on a specified route and rated the safety of each link at checkpoints along the route. The factors that contribute to the BLOS were found to include:

- Vehicle volume on adjacent lane

- Posted speed limit

- Percentage of heavy vehicles

- Frequency driveways and on-street parking spaces

- Pavement surface condition

- Width of pavement between the outside lane stripe and the edge of pavement Other factors were included, but were difficult to measure.

A better measure is the Bicycle Compatibility Index. The BCI was developed by the Highway Safety Research Center at the University of North Carolina. Mid-block roadway segments with varying geometry and traffic conditions were videotaped, and viewed by a diverse group of bicyclists. The bicyclists then gave their perceptions of the safety of the segments. A linear regression model was then developed using geometric properties and traffic conditions as predictors of the bicyclists' ratings. The principal BCI factors included:

- Width of Bicycle Lane or Paved Shoulder, if one exists

- Curb Lane Vehicle Volume

- 85th Percentile Speed of Traffic

- Presence of a Parking Lane With More Than 30\% Occupancy 
- Truck Volumes, Parking Turnover, and Right Turn Volumes

The variable with the largest effect on the $\mathrm{BCI}$ is the presence or absence of a bicycle lane or paved shoulder. Data to explain when bicyclists choose to ride on a sidewalk, even when a bicycle lane is available, are being collected informally outside of (but inspired by) this project.

\subsection{Bicycle Network Analysis}

As the words underlined in the previous section indicate, the factors were identified with a focus on individual road segments. Because bicyclists go from origin to destination on a series of links that form a route, a network-based analysis seemed to be desirable. In this project, development of a Bicycle Network Analysis Tool (BNAT) was initiated. The results of tests on a variety of scenarios were encouraging. The BNAT can assist in the evaluation of proposed bicycle facilities in the context of a network. Although the test network was only a few square miles in area, the lessons learned in those tests can be applied to a larger bicycle network. The BNAT should be useful for a region that has disjoint bikeways and wants to connect them in a cost-efficient way. The BNAT calculates the change in network performance measures that result from a proposed improvement in one or more elements of the bicycle facilities. At the regional or statewide scale, the BCI factors and their coefficients may have to be adjusted, but the ability to assess the impacts of investments in one or more links would be helpful in adding to a bicycle network. 


\subsection{Study Advisory Committee Recommendations}

At their final meeting, the SAC members asked that the final report contain a series of recommendations that support programs that enhance bicycle safety. These recommendations include:

A. Establish supplemental sources of information on bicycle-related crashes. Information on bicycle-related crashes is available on standard INDOT crash reports only if a motor vehicle is involved and property damage exceeds $\$ 750$. NHTSA estimates that only about 17 percent of bicycle crashes involve motor vehicles, so much information about unsafe bicycling conditions is not available through normal reporting methods. One option that has been used is contacting hospitals and doctor's offices for information about bicycle-related injuries, but this is tedious and involves matters of privacy.

B. Better crash report forms. The crash report forms, recently modified, are designed to describe motor vehicle crashes. Bicyclists and pedestrians are considered in an incidental way.

- Under "primary factors" and "contributing factors", "pedestrian action" was often cited on the crash forms when bicyclists were involved, but this category includes both pedestrians and pedalcyclists. Separating the categories would help analyses such as that attempted for this study. Any information on erratic bicyclist behavior could be very helpful.

- An entry for "safety equipment used" by bicyclists. There is now no specific place for the use (or non-use) of helmets, reflectors, or lights on the form. 
This is likely a major contributing factor in many bicycle crashes and their severity, but it is not a part of the standard form.

C. A set of design criteria for possible inclusion in the Indiana Design Manual. The general recommendation by the $\mathrm{SAC}$ is that bicycle facilities on new and reconstructed roadways be included in every project, unless special circumstances require their absence. A recent example is the US231 Relocation Project in West Lafayette, in which a paved shoulder along South River Road is available for bicycle use. (See Figure 28.) Although this is not now a road used by many bicyclists, it has been used by some bicyclists, can be serve as a paved shoulder for motor vehicles, and may some day be part of a bicycle network.

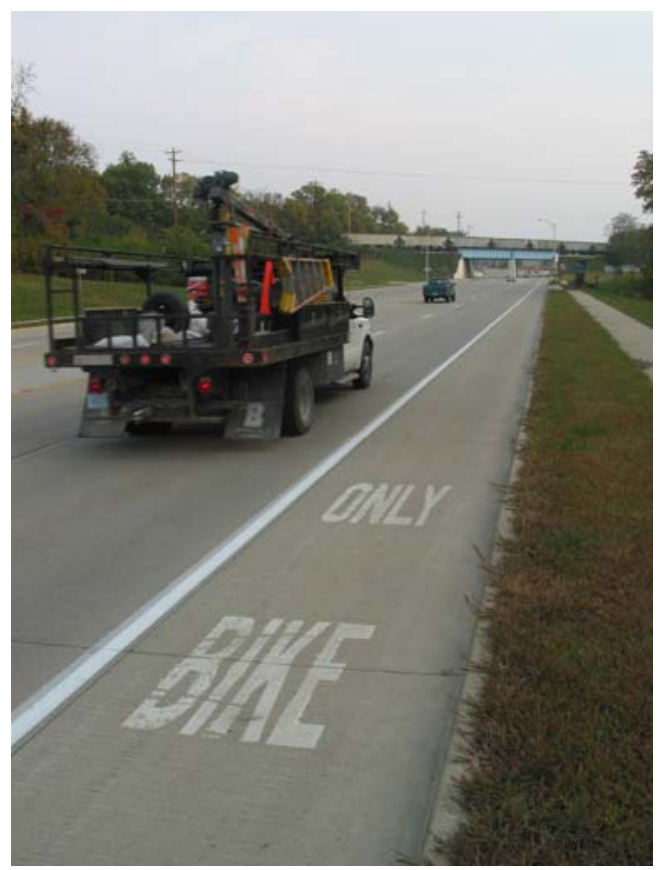

Figure 28 US231 South of SR26 Unfortunately, the bicycle component of a design is forgotten. Examples are:

- Getting bicycle traffic through entrances to ramps that serve limited access facilities. One SAC member cited Main Street in Greenwood at Emerson, and at I-65. Another member mentioned $71^{\text {st }}$ Street at the I-65 ramp near Eagle Creek Park.

- The project to add two lanes to SR62 near the north entrance to Clifty Falls State Park in Jefferson County creates what some call a bicycle-unfriendly 
environment. Entrances to State Parks should offer special consideration to bicyclists, but that is not the case there.

D. Education. The Indiana Bicycle Coalition (IBC) sponsors numerous activities to educate bicyclists and those who share the road with them. Of particular interest are compliance with road signs and traffic laws, keeping adequate separation between motor vehicle and bicyclist while overtaking, wearing light-colored clothing, and using reflectors and lights on bicycles and/or bicyclists during times of limited light or visibility. The IBC would welcome an increased partnership with INDOT to promote this alternative transportation mode.

E. Partnerships with target groups.

- If an examination of the race of individual bicyclists involved in crashes shows groups more frequently involved than the norm, a targeted information/education campaign could be devised. For example, a NHTSAsponsored study (Knoblauch and Seifert 2004) determined that "Hispanic immigrants and persons of Hispanic descent are involved in a disproportionate number of pedestrian and bicyclist crashes."

- The Governor's Council on Impaired \& Dangerous Driving (GCIDD) gets Section 4023 funds, not INDOT. To the SAC members' knowledge, there have been no GCIDD programs aimed at bicycle and pedestrian issues. Perhaps the GCIDD would accept some ideas for ped/bike programs. See Item $\mathrm{D}$ above.

- Some SAC members believe that some fast food restaurant employees are more likely to ride bicycles to work. Some of the commuting rides may occur 
at times of limited or no daylight. As part of their training program, brief coverage of bicycle safety tips could be presented. Providing a light suitable for use by bicyclists to interested employees could be part of a sponsored giveaway and education program. The Indiana Bicycle Coalition has a 20minute Effective Bicycling video that could be made available.

\subsection{Research Opportunities}

This project was a "feasibility study", designed to investigate basic issues regarding bicycle use, roadway design, and facility planning. In addition to the findings presented earlier, a number of questions arose that might form the basis for subsequent research. Among the opportunities for future research are:

A. Bicycle origin-destination data and trip length distribution, by trip type (commute vs. leisure). Some trip length data have been collected on bicycle paths in the Indianapolis area by Prof. Lindsey of IUPUI. Information on origins of bicycle trips to Purdue's West Lafayette campus (most of which use city streets and sidewalks) was collected as part of a class project by Prof. Fricker in Fall 2006. The results were promising, but developing a database large enough to support statistically reliable conclusions would take the resources of a formal research project.

B. Bicyclist route choice behavior, based on facility, trip type, and bicyclist characteristics. As part of the Purdue class project mentioned in Item A above, students are attempting to ask bicyclists to describe the routes they use to get to campus. It is likely that route choice varies from one bicyclist to another, 
depending on individual perceptions regarding the feasible paths to campus. Unfortunately, only 30 routes that used off-campus streets were captured by the survey effort. The value of a more extensive survey was justified, however.

C. Testing and modifying The BNAT using real O-D and facility data. In this project, the BNAT was tested using a trip table that was fabricated on the simplified premise that each pair of intersections in the study area constituted an origin-destination pair for a bicycle trips. In reality, bicycle trip ends are not so evenly distributed. The results of Items A and B above will permit a better specification of the BCI component of The BNAT model. Extending The BNAT to leisure trips and bike paths will make the BNAT more useful. Another significant issue is the impact of intersections. Alternate ways of including intersections in the BNAT would need to be investigated.

D. Integrate The BNAT with the recently formulated Statewide Bicycle Plan. The roadway characteristics in INDOT's Roadway Inventory File should provide a sufficient basis for developing a state-level BNAT. The results of Items A and B above would add the missing data that are needed by The BNAT. The BNAT was developed using the same software that is used by the Indiana Statewide Travel Demand Model and most MPOs in Indiana, so data entry and manipulation would be minimized.

E. Helmet reflectivity. It has not clear to what extent the reflective aspects of a bicycle helmet are guided by government regulation or based on sufficient research. A search of regulations and literature may reveal that more study is needed on this subject. 


\section{LIST OF REFERENCES}

1. Harkey, David L., Donald W. Reinfurt, Matthew Knuiman, J. Richard Stewart, Alex Sorton. "Development of a Bicycle Compatibility Index: A Level of Service Concept." UNC Highway Safety Research Center. December 1998. Chapel Hill, NC. http://www.hsrc.unc.edu/research/pedbike/98095/index.html

2. Knoblauch, Richard L. and Rita Furst Seifert, “The Pedestrian and Bicyclist Highway Safety Problem As It Relates to the Hispanic Population in the United States", FINAL REPORT DTFH61-03-P-00324, Center for Applied Research, Inc., Great Falls, VA, December 30, 2004

3. Landis, B.W., V.R. Vattikuti, and M.T. Brannick, "Real-time Human Perceptions: Toward a Bicycle Level of Service,"Transportation Research Record 1578, Transportation Research Board, Washington, DC, 1997.

4. UNC Highway Safety Research Center, "Benefit Cost Analysis of Bicycle Facilities". Pedestrian and Bicycle Information Center, University of Minnesota Department of Civil Engineering, Planners Collaborative, Active Living by Design. 5 July 2006. <http://www.bicyclinginfo.org/bikecost/>

5. Vehicle Crash Records System. Bicycle Crash Report Database. Provided by the Center for the Advancement of Transportation Safety, West Lafayette IN, 13 June 2006. 